\title{
Paradox of schizophrenia genetics: is a paradigm shift occurring?
}

Nagafumi Doi ${ }^{1 *}$, Yoko Hoshi ${ }^{2}$, Masanari Itokawa ${ }^{3}$,Takeo Yoshikawa ${ }^{4}$,Tomoe Ichikawa ${ }^{3}$, Makoto Arai ${ }^{3}$, Chie Usui $^{5}$ and Hirokazu Tachikawa ${ }^{6}$

\begin{abstract}
Background: Genetic research of schizophrenia (SCZ) based on the nuclear genome model (NGM) has been one of the most active areas in psychiatry for the past two decades. Although this effort is ongoing, the current situation of the molecular genetics of SCZ seems disappointing or rather perplexing. Furthermore, a prominent discrepancy between persistence of the disease at a relatively high prevalence and a low reproductive fitness of patients creates a paradox. Heterozygote advantage works to sustain the frequency of a putative susceptibility gene in the mitochondrial genome model (MGM) but not in the NGM.
\end{abstract}

Methods: We deduced a criterion that every nuclear susceptibility gene for SCZ should fulfill for the persistence of the disease under general assumptions of the multifactorial threshold model. SCZ-associated variants listed in the top 45 in the SZGene Database (the version of the $23^{\text {rd }}$ December, 2011) were selected, and the distribution of the genes that could meet or do not meet the criterion was surveyed.

Results: 19 SCZ-associated variants that do not meet the criterion are located outside the regions where the SCZ-associated variants that could meet the criterion are located. Since a SCZ-associated variant that does not meet the criterion cannot be a susceptibility gene, but instead must be a protective gene, it should be linked to a susceptibility gene in the NGM, which is contrary to these results. On the other hand, every protective gene on any chromosome can be associated with SCZ in the MGM. Based on the MGM we propose a new hypothesis that assumes brain-specific antioxidant defenses in which trans-synaptic activations of dopamine- and N-methyl-Daspartate-receptors are involved. Most of the ten predictions of this hypothesis seem to accord with the major epidemiological facts and the results of association studies to date.

Conclusion: The central paradox of SCZ genetics and the results of association studies to date argue against the NGM, and in its place the MGM is emerging as a viable option to account for genomic and pathophysiological research findings involving SCZ.

Keywords: Mutation-selection balance, Heterozygote advantage, Sex difference, MtDNA, Gene-gene interaction, Gene-environment interaction, Protective gene, Mitochondrial dysfunction, Oxidative stress, Genomic instability

\section{Background}

Schizophrenia (SCZ) is a common and highly heritable form of psychosis associated with a remarkable biological disadvantage [1]. Accordingly, the central paradox of SCZ genetics is how susceptibility genes are preserved in the human gene-pool against a strong negative selection pressure [2-5]. Although recent large-sample epidemiological

\footnotetext{
* Correspondence: n.doi@pref.ibaraki.lg.jp

${ }^{1}$ Ibaraki Prefectural Medical Center of Psychiatry, 654Asahi-machi, Kasama-shi, Ibaraki 309-1717, Japan

Full list of author information is available at the end of the article
}

studies [6-9] have consistently shown that the reproductive fitness of the unaffected female siblings of patients with SCZ is slightly increased (1.02-1.08), it is not large enough to compensate for the gene loss due to the decreased reproductive fitness of patients (0.2-0.3 in males and 0.4-0.5 in females) and their unaffected male siblings (0.9-1.0) in the nuclear genome model (NGM). Furthermore, the latest meta-analysis shows that parents of patients with SCZ have fertility similar to the general population [10]. Therefore, heterozygote advantage does not seem to work in the NGM.

\section{Biomed Central}

(C) 2012 Doi et al.; licensee BioMed Central Ltd. This is an Open Access article distributed under the terms of the Creative Commons Attribution License (http://creativecommons.org/licenses/by/2.0), which permits unrestricted use, distribution, and reproduction in any medium, provided the original work is properly cited. 
However, it works in the mitochondrial genome model (MGM) because mtDNA is transmitted to the next generation only through females. Indeed, we can see that this slightly elevated fitness of the unaffected female siblings, coupled with the less pronounced decreased fitness of female patients, is sufficient to compensate for the gene loss in the MGM; when we calculate $-\Delta$, the cross-generational reduction of the frequency of females carrying putative pathogenic mtDNA in the general population, using data from the largest-sampled cohort study to date [8], we have $-\Delta<5.06 \times 10^{-3}[11]$. This figure implies that the gene loss can be balanced by de novo mutation in the mtDNA which occurs at a rate of $8.8 \times 10^{-4} \sim 1.3 \times 10^{-2}$ per locus per generation $\left(4.3 \times 10^{-3}\right.$ on average $)[12]$.

Thus, in our previous paper [11], we carefully reexamined the necessary conditions for putative nuclear susceptibility genes for SCZ and deduced a criterion (the persistence criterion, or 'P-criterion') for nuclear susceptibility genes for SCZ based on the general assumptions of the multifactorial threshold model. Because SCZ must be sustained by mutation-selection balance without heterozygote advantage in the NGM and the mutation rates in the nuclear genome are much lower than in the mitochondrial genome [12-14], the criterion is strong. It demands $0<$ $d<v \equiv \frac{(1-s p) \mu}{(1-p) s p}$ (Appendix A), while the principle of association study demands $d>0$. Here $d, \mu, p$ and $s$ denote the case-control difference of allele frequencies, the mutation rate at a putative risk locus, and the prevalence and the selection coefficient of the disease respectively. According to epidemiological data collected by Haukka et al. [8] $\left(p=1.29 \times 10^{-2}\right.$ and $\left.s=6.54 \times 10^{-1}\right), v$ is very small for SCZ. Given the average mutation rate in the autosomes and the $\mathrm{X}$ chromosome $\left(\mu=1.48 \times 10^{-5}\right)$, we have $v=1.76 \times 10^{-3}$, and given the highest mutation rate $\left(\mu=1.48 \times 10^{-4}\right)$, we have $v=1.76 \times 10^{-2}$ (Appendix B).

Using this criterion, we can calculate a lower boundary for the sample size required in an association study of a given power (Appendix $\mathrm{C}$ ). Thus, we can see that more than 29,000 case-control pairs are required in a genome-wide association study (GWAS) with a power of 0.8 to detect a susceptibility variant of the highest mutation rate and a population frequency between 0.005 and 0.995 , and that more than 2.9 million case-control pairs are required in a GWAS with a power of 0.8 to detect a susceptibility variant of the average mutation rate and a population frequency between 0.0005 and 0.9995 .

In the past two decades, mitochondrial dysfunction (MD) in SCZ has been suggested by several independent lines of evidence [15-18], that include mitochondrial hypoplasia, elevated oxidative stress (OS), disturbed oxidative phosphorylation (OXPHOS), and altered mitochondrialrelated gene expression in several cell lines. It is still unknown whether MD in the brains of patients with SCZ is a primary pathogenic change or a secondarily induced process, and the aforementioned inconclusive findings create more questions than answers about the origin of SCZ. We contend, however, that the MGM may very well have the answers.

In the present study, we apply the P-criterion to the results of association studies to date and survey the distribution of SCZ-associated genes that could meet or do not meet the P-criterion. We discuss why those SCZassociated genes that do not meet the criterion must be protective genes (PGs) for $\mathrm{SCZ}$, and suggest that the MGM can replace the NGM as a basis for genomic research of SCZ. Based on the MGM we propose a new hypothesis that assumes brain-specific antioxidant defenses in which neurotransmissions are involved, and present ten predictions of the hypothesis.

\section{Methods}

SCZ-associated variants listed in the top 45 in the SZGene Database [19] (the version of the $23^{\text {rd }}$ December, 2011) were selected. Based on the genotype distributions in the meta-analyses, allele frequencies and the case-control differences were calculated.

\section{Results and discussion}

\section{Distribution of SCZ-associated variants that could meet the P-criterion}

Association studies to date have detected many SCZassociated genes on various chromosomes [19,20]. However, most of these do not meet the criterion; only 21 variants on18 loci in the top 45 genes in the SZGene Database could meet the criterion under the assumption that the mutation rates at those loci are near the upper limit on the autosomes and the X chromosome (Tables 1 and 2). In other words, association studies have detected only a few susceptibility genes in the NGM, if any, that produce small effects (in most cases OR $<1.4$ ). Association studies to date (sample size $<50,000$ case-control pairs) may lack the power to detect pathogenic variants of less than the highest mutation rates. The question remains: how many samples would be required to detect them?

The P-criterion implies that an enormous sample size is required to identify a pathogenic variant of the average mutation rate. Indeed, more than 2.9 million case-control pairs should be recruited to a GWAS to identify a susceptibility variant of a population frequency between 0.0005 and 0.9995 with a power of 0.8 (Appendix C). If the mutation rate at a putative risk locus is relatively low $\left(\mu=1.48 \times 10^{-6}\right)$, more than 290 million case-control pairs are required in a GWAS to detect a risk variant of a population frequency between 0.000005 and 0.999995 with a power of 0.8 (Appendix C). Since the total human population today is $\sim 7$ billion [21] and the overall prevalence of SCZ is $\sim 0.7 \%$ [22], the total number of patients 
Table 1 SCZ-associated variants on chromosome 1 that could meet or do not meet the criterion in the Top $\mathbf{4 5}$ genes at the SZGene Database [19] (Updated Dec 23, 2011)

\begin{tabular}{|c|c|c|c|c|c|c|}
\hline $\begin{array}{l}\text { Genes and } \\
\text { SNPs }\end{array}$ & Location & $\begin{array}{c}\text { Allele } \\
\text { (min/maj) }\end{array}$ & $m_{A}$ & $m_{U}$ & $O R$ & $d$ \\
\hline MHTFR & $1 p 36.22$ & & & & & \\
\hline rs1801133 & & $\mathrm{T}^{*} / \mathrm{C}$ & 0.3532 & 0.3211 & 1.15 & 0.032 \\
\hline GRIK3 & $1 p 34.3$ & & & & & \\
\hline rs6691840 & & $\mathrm{G}^{*} / \mathrm{T}$ & 0.2600 & 0.2226 & 1.25 & 0.037 \\
\hline$P D E 4 B$ & $1 p 31.3$ & & & & & \\
\hline rs910694 & & $C / T^{*}$ & 0.5780 & 0.5477 & 1.30 & 0.030 \\
\hline GSTM1 & $1 \mathrm{p} 13.3$ & & & & & \\
\hline GSTM ${ }^{*} 0$ & & $\begin{array}{l}\text { ins-allele/ } \\
\text { del-allele* }\end{array}$ & 0.7546 & 0.7140 & 1.35 & 0.041 \\
\hline RGS4 & $1 q 23.3$ & & & & & \\
\hline rs2661319 & & $A / G^{*}$ & 0.4920 & 0.4744 & 1.08 & 0.0176 \\
\hline IL10 & $1 q 32.1$ & & & & & \\
\hline rs1800896 & & $\mathrm{G}^{*} / \mathrm{A}$ & 0.3056 & 0.2657 & 1.42 & 0.040 \\
\hline PLXNA2 & $1 q 32.2$ & $\mathrm{~A} / \mathrm{G}$ & & & & \\
\hline rs841865 & & $\mathrm{A} / \mathrm{G}^{*}$ & 0.8434 & 0.8001 & 1.32 & 0.043 \\
\hline rs1327175 & & $\mathrm{G} / \mathrm{C}^{*}$ & 0.92840 & 0.91243 & 1.32 & 0.016 \\
\hline DISC1 & $1 q 42.3$ & & & & & \\
\hline rs3737597 & & $A^{*} / G$ & 0.03069 & 0.01735 & 1.80 & 0.013 \\
\hline rs999710 & & $A * / G$ & 0.3989 & 0.3819 & 1.07 & 0.0170 \\
\hline
\end{tabular}

Four variants at the three loci (RGS4, PLXNA2, DISC1) on chromosome 1 could meet the criterion under the assumption that the mutation rates at those loci are near the upper limit in the autosomes and the $X$ chromosome. All of them are located on 1q, while four protective genes (MHTFR, GRIK3, PDE4B, GSTM1) are on $1 \mathrm{p}$.

*alleles associated with SCZ.

with SCZ in the world today is $\sim 49$ million. Therefore it would take more than several hundred years to gather the required number of samples even if all of the affected individuals in the world were to be recruited. The journey to search for susceptibility genes for SCZ in the NGM seems far more difficult and would take longer than previously thought.

\section{Distribution of SCZ-associated variants that do not meet the criterion}

Now, let us consider the nature of those SCZ-associated genes that do not meet the criterion. The inequality $d \geq v$ implies $s_{M}<s$, where $s_{M}$ and $s$ denote the selection coefficient in the affected subpopulation with an allele $\mathrm{M}$ and in the affected population as a whole respectively (Appendix A); otherwise, the frequency of $\mathrm{M}$ in the affected population must have been decreased to the same level in the unaffected population. Therefore, such genes, if sustained by mutation-selection balance, cannot be susceptibility genes but instead are PGs that decrease the risk and the severity of the disease.
Since a PG in the NGM cannot be associated with the disease unless it is linked to a susceptibility gene, PGs in the NGM should be located in the vicinity of susceptibility genes, something that is contrary to the results of association studies to date. For example, on chromosome 1, all of the SCZ-associated genes that could meet the criterion (RGS4, PLXNA2, DISC1) are located on 1q, while 4 PGs (MHTFR, GRIK3, PDE4B, GSTM1) are on 1p (Table 1). 15 PGs are located on 2q, 5q, 7q, 10q, 11p, 12p, 12q, 13p, $13 q, 16 p, 17 p$, and 19q, where no SCZ-associated variants that could meet the criterion are located (Table 2). Therefore, the results of association studies to date do not support the NGM.

The only plausible interpretation that accords with the NGM may be that many nuclear susceptibility genes of less than the highest mutation rates have not been detected by association studies to date due to lack of power. If we assume this case, however, an enormous sample size (more than 2.9 290 million case-control pairs) would be required to identify them. Although the possibility of the NGM cannot be entirely denied, the proof of the NGM may be extremely difficult because it requires such an enormous sample size.

\section{The MGM is compatible with the results of association studies to date}

A case can be made for the MGM however, because every PG on any chromosome can be associated with SCZ in the MGM. This is because mtDNA is transmitted only via females and there is no link between the nuclear genome and the mitochondrial genome; such that every nuclear genome that interacts with a pathogenic mitochondrial genome to alter the risk and the severity of the disease is subject to natural selections in the predisposed maternal lineage that succeeds the same pathogenic mitochondrial genome. Therefore, in the MGM every PG on any chromosome is subject to positive selection in the predisposed maternal lineage, and is thereby associated with SCZ.

Thus, the MGM is compatible with the results of association studies to date.

It should be noted that in the MGM the frequency of every facilitating gene (FG; a gene that increases the risk and the severity of SCZ in the presence of a pathogenic mitochondrial genome) on any chromosome may diminish in the predisposed matrilineal pedigrees by negative selection; thereby, negatively associating with SCZ.

\section{mtDNA hypothesis for SCZ as an alternative genetic model}

Based on the MGM, we propose a new genetic hypothesis for SCZ. It consists of two parts: $\mathrm{H} 1$ and $\mathrm{H} 2$.

H1: Pathogenic genes for SCZ are located in the mitochondrial genome and embryos from fertilized 
Table 2 SCZ-associated variants on chromosome 2-22 and the chromosome $X$ that could meet or do not meet the criterion in the Top 45 genes at the SZGene Database (Updated Dec 23, 2011)

\begin{tabular}{|c|c|c|c|c|c|c|}
\hline Genes and SNPs & Location & Allele (min/maj) & $m_{A}$ & $m_{U}$ & $O R$ & $d$ \\
\hline \multicolumn{7}{|l|}{ Chromosome 2} \\
\hline ILIB & $2 q 13$ & & & & & \\
\hline rs16944 & & $T / C^{*}$ & $0.6289(\mathrm{~N}=1,718)$ & $0.6066(\mathrm{~N}=2,157)$ & 1.11 & 0.022 \\
\hline ZNF804A & $2 q 32.1$ & & & & & \\
\hline rs1344706 & & $\mathrm{G} / T^{*}$ & $0.6357(\mathrm{~N}=6,487)$ & $0.6032(\mathrm{~N}=11,478)$ & 1.14 & 0.033 \\
\hline \multicolumn{7}{|c|}{ Chromosome 3: none } \\
\hline \multicolumn{7}{|l|}{ Chromosome 4} \\
\hline CCKAR & $4 p 15.2$ & & & & & \\
\hline rs1800857 & & $C^{*} / T$ & $0.1666(\mathrm{~N}=105)$ & $0.1559(\mathrm{~N}=93)$ & 1.32 & 0.008 \\
\hline \multicolumn{7}{|l|}{ Chromosome 5} \\
\hline GABARB2 & $5 q 34$ & & & & & \\
\hline rs1816072 & & $C / T^{*}$ & $0.6404(\mathrm{~N}=1,129)$ & $0.5935(\mathrm{~N}=995)$ & 1.22 & 0.047 \\
\hline rs194072 & & $C / T^{*}$ & $0.8685(\mathrm{~N}=1,137)$ & $0.8466(\mathrm{~N}=991)$ & 1.20 & 0.022 \\
\hline rs6556547 & & $T / G^{*}$ & $0.9444(\mathrm{~N}=774)$ & $0.9226(\mathrm{~N}=620)$ & 1.43 & 0.022 \\
\hline
\end{tabular}

CMYAS5 (5q14.1; rank 24) is excluded because there are no available data on the genotype distribution.

Chromosome 6

DTNBP1

rs3213207

rs1474605

HIST1H2BJ

rs6913660

PRSS16

rs6932590

rs13219354

PGBD1

rs13211507

RPP21

rs3130375

NOTCH4

rs3131296

rs 2071287

\section{MDGA1}

rs11759115

rs12191311

rs7769372

AH1

rs2064430

rs11154801

C6orf217

rs10223338

rs1475069

rs9321521
$6 p 23$

$\mathrm{G} / \mathrm{A}^{*}$

$0.8891(\mathrm{~N}=8,377)$

$0.8758(\mathrm{~N}=8,886)$

1.11

0.013

$\mathrm{G} / \mathrm{A}^{*}$

$0.8000(\mathrm{~N}=3,710)$

$0.7858(\mathrm{~N}=3,588)$

1.09

0.014

$6 p 22.1$

$\mathrm{A} / \mathrm{C}^{*}$

$0.8927(\mathrm{~N}=10,065)$

$0.8801(\mathrm{~N}=34,098)$

1.15

0.013

$6 p 22.1$

$\mathrm{C} / \mathrm{T}^{*}$

$\mathrm{C} / \mathrm{T}^{*}$

$0.7943(N=7,177)$

$0.8058(\mathrm{~N}=28,270)$

1.16

$0.9020(\mathrm{~N}=27,224)$

1.20

$-0.012$

$6 p 22.1$

$\mathrm{C} / \mathrm{T}^{*}$

$0.9518(\mathrm{~N}=9,774)$

$0.9387(\mathrm{~N}=33,694)$

1.23

0.013

6p21.33

$\mathrm{A} / \mathrm{C}^{*}$

$0.9018(N=2,799)$

$0.8634(\mathrm{~N}=3,082)$

1.41

0.038

$6 p 21.32$

$A / G^{*}$

$0.8912(\mathrm{~N}=7,156)$

$0.8892(\mathrm{~N}=28,312)$

1.20

0.002

$A / G^{*}$

$0.6858(\mathrm{~N}=2,511)$

$0.6463(\mathrm{~N}=2,556)$

1.19

0.039

$6 p 21.2$

$C / T^{*}$

$0.8639(N=1,874)$

$0.8379(N=2,582)$

1.23

0.026

$\mathrm{T} * \mathrm{C}$

$0.3619(\mathrm{~N}=1,879)$

$0.3555(\mathrm{~N}=2,605)$

1.12

0.006

$\mathrm{T}^{*} / \mathrm{C}$

$0.2328(N=1,915)$

$0.1885(\mathrm{~N}=2,576)$

1.18

0.044

$6 q 23.3$

$\mathrm{T}^{*} / \mathrm{C}$

$0.5672(N=2,796)$

$0.5296(N=13,494)$

1.13

0.038

$\mathrm{A} / \mathrm{C}^{*}$

$0.6633(\mathrm{~N}=3,298)$

$0.6576(\mathrm{~N}=14,805)$

1.09

0.006

$6 q 23.3$

$\mathrm{T} / \mathrm{C}^{*}$

$0.7158(\mathrm{~N}=2,797)$

$0.6975(N=13,522)$

1.12

0.018

$C^{*} / \mathrm{A}$

$0.7205(\mathrm{~N}=3,276)$

$0.6976(N=14,639)$

1.14

0.023

$A / G^{*}$ 
Table 2 SCZ-associated variants on chromosome 2-22 and the chromosome $X$ that could meet or do not meet the criterion in the Top 45 genes at the SZGene Database (Updated Dec 23, 2011) (Continued)

Chromosome 7

RELN

rs7341475

rs262355

Chromosome 8

PPP3CC

rs2461491

rs10108011

SLC18A1

rs2270641

NRG1

rs10503929

Chromosome 9: none

Chromosome 10

GWA_10q26.13

rs17101921

Chromosome 11

DRD4
rs4646984
rs1800955
TPH1
rs1800532
rs1799913
GWA_11p14.1
rs1602565

DRD2

rs6277

rs6275

rs1801028

NRGN

rs12807809

OPCML

rs3016384

Chromosome 12

GRIN2B

rs1019385

DAO

rs4623951

Chromosome 13

HTR2A

rs6311

DAOA

rs778293

rs3916971

$$
7 q 22.2
$$

$\mathrm{A} / \mathrm{G}^{*}$

$A^{*} / T$

8p21.3

$A * / G$

G*/A

$8 p 21.3$

$8 p 12$

$C^{*} / A$

$\mathrm{C} / \mathrm{T}^{*}$

$0.4469(\mathrm{~N}=6,287)$

$0.3657(\mathrm{~N}=4,304)$

$0.4353(\mathrm{~N}=6,200)$

$0.3488(\mathrm{~N}=4,465)$

1.07

1.09

0.015

$0.3182(N=759)$

$0.8342(N=3,256)$

$0.2802(\mathrm{~N}=885)$

1.63

0.038

$0.8118(N=4,181)$

1.14

0.022

$10 q 26.11$

$A^{*} / G$

$0.06667(\mathrm{~N}=7,447)$

$0.04318(\mathrm{~N}=13,039)$

1.28

0.023

11 p15.5
$S / L^{*}$

$\mathrm{C}^{*} / \mathrm{T}$

$11 p 15.1$

$11 \mathrm{p} 14.1$

$11 \mathrm{q} 23.1$

$A^{*} / C$

$A^{*} / C$

$C^{*} / T$

$0.1346(\mathrm{~N}=5,475)$

$0.4968(N=3,156)$

$0.3106(\mathrm{~N}=2,436)$

$0.0245(\mathrm{~N}=4,304)$

$11 \mathrm{q} 24.2$

$11 \mathrm{q} 25$

$\mathrm{C} / \mathrm{T}^{*}$

$T / C^{*}$

$12 \mathrm{p} 13.1$

$12 q 24.11$

$\mathrm{T} / \mathrm{G}^{*}$

$\mathrm{C} / \mathrm{T}^{*}$

$0.8403(N=7,213)$

$0.5374(\mathrm{~N}=5,491)$

$0.5141(\mathrm{~N}=10,900)$

1.10

0.023

$0.4527(\mathrm{~N}=3,960) \quad 1.40 \quad 0.044$

$0.2927(\mathrm{~N}=2,918) \quad 1.15 \quad 0.018$

$0.0207(\mathrm{~N}=5,920)$

1.33

0.004

$0.8190(N=28,490)$

1.15

0.021

$0.5604(\mathrm{~N}=687)$

$0.4885(N=650)$

1.33

0.072

$0.7038(N=1,509)$

$0.6788(N=1,521)$

1.14

0.025

$13 p 14.13$

$13 q 33.3$

$A^{*} / G$

$0.4441(\mathrm{~N}=2,594)$

$0.4115(\mathrm{~N}=2,869)$

1.21

0.033

$\mathrm{G}^{*} / \mathrm{A}$

$0.3149(\mathrm{~N}=2,899)$

$0.2770(N=3,218)$

1.18

0.038

$\mathrm{T} / \mathrm{C}^{*}$

$0.5622(\mathrm{~N}=844)$

$0.5211(\mathrm{~N}=922)$

1.19

0.041 
Table 2 SCZ-associated variants on chromosome 2-22 and the chromosome $X$ that could meet or do not meet the criterion in the Top 45 genes at the SZGene Database (Updated Dec 23, 2011) (Continued)

Chromosome 14

AKT1

$14 q 32.33$

rs3803300

$A^{*} / G$

$0.1068(\mathrm{~N}=1,301)$

$0.1039(\mathrm{~N}=1,424)$

1.36

0.003

Chromosome 15: none

Chromosome 16

GWA_16p13.12

$16 p 13.12$

rs7192086

$0.2701(N=7,179)$

$0.2456(N=12,623)$

1.12

0.025

RPGRIP1L

$16 q 12.2$

rs9922369

$A^{*} / G$

$0.0403(\mathrm{~N}=6,494)$

$0.0336(\mathrm{~N}=11,449)$

1.32

0.007

HP

$16 q 22.3$

Hp_1/2

$1 / 2^{*}$

$0.6208(N=1,300)$

$0.5911(\mathrm{~N}=1,976)$

1.14

0.030

Chromosome 17

SRR

$17 p 13.3$

rs408067

$\mathrm{G}^{*} / \mathrm{A}$

$0.3166(\mathrm{~N}=1,145)$

$0.2779(\mathrm{~N}=1,146)$

1.22

0.039

Chromosome 18

TCF4

rs9960767

$18 q 21.2$

C*/A

$0.0514(\mathrm{~N}=9,755)$

$0.0467(\mathrm{~N}=33,648)$

1.23

0.005

Chromosome 19

APOE

e4-allele

$19 q 13.32$

Chromosome 20: none

Chromosome 21: none

Chromosome 22

COMT

$22 q 11.21$

rs737865

$\mathrm{C} / \mathrm{T}^{*}$

$0.6916(\mathrm{~N}=7,397)$

$\mathrm{G}^{*} / \mathrm{C}$

$0.3503(\mathrm{~N}=177)$
$0.6803(\mathrm{~N}=10,411)$

1.06

1.05
0.011

0.042

Chromosome X: none

On chromosomes 2-22 and the chromosome $\mathrm{X}, 17$ variants at 15 loci (CCKAR, DTNBP1, HIST1H2BJ, PRSS16, PGBD1, NOTCH4, MDGA1, AH1, C6orf217, PPP3CC, DRD2, $A K T 1$, RPGRIP1L, TCF4, COMT) could meet the criterion under the assumption that the mutation rates at those loci are near the upper limit in the autosomes and the $X$ chromosome. 15 protective genes (IL1B, ZNF804A, GABARB2, RELN, GWA_10q26.13, DRD4, TPH1, GWA_11p14.1, GRIN2B, DAO, HTR2A, DAOA, GWA_16p13.12, $S R R, A P O E)$ are located on 2q, 5q, 7q, 10q, 11p, 12p, 12q, 13p, 13q, 16p, 17p, and 19q, where no SCZ-associated variants that could meet the criterion are located *alleles associated with SCZ.

oocytes with mutation loads over a certain threshold can develop the disease. The threshold is determined by the interactions with the environmental and nuclear genetic factors.

H2: Disturbed OXPHOS and OS play central roles in the pathophysiology of SCZ, causing a variety of changes. Those include adaptive responses of the brain that are relevant to the exacerbation of the illness.

\section{Pathophysiological aspect of SCZ and the MGM}

Mitochondria are involved in a variety of major cellular events such as OXPHOS, free radical production and $\mathrm{Ca}^{2}$ + buffering, and play an active role in apoptosis. They possess two classes of antioxidant defenses (non-enzymatic or enzymatic) [23], and structurally and functionally intact mitochondria serve as a net sink rather than a net source of reactive oxygen species (ROS). ROSdefenses are severely undermined in structurally compromised mitochondria [23], and MD, presumably through imbalance of ROS production and removal [23], raises ROS emission [24,25], causing a strong intracellular OS.

Mitochondrion has dual genetic bases (ncDNA and mtDNA), and there are 37 loci in the mtDNA (22 tRNAs, 2 rRNAs, and all of the 13 OXPHOS subunits: ND1, ND2, ND3, ND4, ND4L, ND5, ND6, CO1, CO2, CO3, CYB, ATPase6, and ATPase8). Therefore, abnormal mtDNA may cause disturbed OXPHOS and enhanced OS. 
In the past decade, MD in SCZ has been suggested by several independent lines of evidence (for review, see [15-18]); those include increased OS, mitochondrial hypoplasia, disturbed OXPHOS, and altered mitochondrialrelated gene expression in several cell lines.

The pioneering works in this field are noteworthy. As early as 1950, Hayashi [26], in a longitudinal study on glucose metabolites in blood sampled from the superior bulb of the internal jugular vein of patients with SCZ, observed a lower degree of carbonic dioxide production in the brain and a higher level of lactate and glutathione, the brain's dominant free radical scavenger, in patients in an acute exacerbation of the illness. Utena and Ezoe (1951) [27] reported decreased glucose consumption in vitro in cortical brain tissues sampled from patients with SCZ who underwent prefrontal leukotomy. Takahashi (1953) [28] confirmed this finding and recommended further investigations on OXPHOS in the brain tissue of schizophrenics. In line with those findings was the report by Stabenau et al. (1969) [29], who observed in a biochemical study of discordant monozygotic twin pairs that lactate production and the lactate-pyruvate ratios were higher in the affected twins than in the unaffected co-twins. More recently, Prabakaran et al. (2004) [30], in a large-scale functional genomics study, suggested a state of intermittent or chronic hypoxic stress and $\mathrm{MD}$ in the brains of patients with SCZ.

There has been consistent evidence for higher incidence of underdevelopment of muscular system in patients with SCZ [31]. Many authors have confirmed the Kretchmer's observation (1925) of a greater incidence of asthenic or leptosomatic constitution in schizophrenic or pre-schizophrenic individuals, which is characterized by narrowness of muscles, small shoulders, flat chest, and little muscular development [31]. These early observations have been supported by later studies of muscle biopsy and/or electromyography, which showed abnormalities of both muscle function (more hypotonus) and muscle morphology (atrophic muscle fibers scattered or in groups, regardless of the patients' motor activities) in SCZ [32-36].

There also have been many case reports that describe patients with mitochondrial disease and neuropsychiatric disorders including SCZ (for review, see [37,38]). Most of the patients have psychotic symptoms as well as fatigue and muscle weakness that preceded the diagnosis of mitochondrial disease. Furthermore, it has been shown that mtDNA, in interaction with ncDNA, modifies learning, exploration, and sensory development as well as the brain morphology in mice [39].

Those findings indicate that abnormal mtDNA could underlie the etiology of SCZ.

The DA hypothesis and NMDA-R hypofunction theory as well as the recent finding of enhanced carbonyl stress in SCZ may be incorporated into the MGM as will be discussed in the following sections.

\section{Contradictory aspects of dopamine-SCZ connection and the MGM}

Substantial evidence has been accumulated that supports aberration in the dopamine (DA) system $[40,41]$ and its interactions with other neurotransmitters [42] in SCZ. This concept (DA hypothesis of SCZ) mainly stems from indirect observations that there is a strong relationship between clinical potency of neuroleptics and their DAD2 receptor affinities in vitro and that DA agonists can induce psychotic symptoms with marked resemblance to SCZ. More recently, Laruelle et al. [43] reported that DA transmission was increased in patients experiencing an acute exacerbation of the illness, but not in patients in a state of remission.

Those findings strongly suggest that increased DA transmission provides a neuronal basis for positive or productive symptoms in SCZ. Since negative symptoms and cognitive impairments that can precede initial psychotic episode are difficult to explain by the increased DA transmission, a plausible interpretation may be that the increased DA transmission in the brain is a secondary process associated with SCZ. However, since excessive DA release seems to cause MD [16] and apoptosis [44], it could produce additional deterioration of the brain function and morphology after psychotic episodes.

On the other hand, Friedhoff and colleagues [45-47] reported some adaptive aspects of the DA system in SCZ, and proposed that the DA system may be a biological stress buffer. This concept is based on a consistent observation that patients responding favourably to neuroleptic treatment showed higher levels of plasma homovanillic acid (HVA), a metabolite of DA, in the pretreatment and/or the early treatment period, resulting in a marked decrease of plasma HVA level in a later steady state $[46,48-50]$. This observation suggests that increased DA turn over in the pre-treatment or early treatment period may be relevant to a certain adaptive process in patients with SCZ. In line with those findings is the discovery of Cys311 of DRD2 polymorphism [51], which is listed in the top 45 in the SZGene. This firstly discovered SCZ-associated variant supresses the internalization of DRD2 and strengthens the DA transmission [52] while the cases carrying this variant show less negative symptom and less cognitive impairment [51].

Then, how can we reconcile those two contradictory aspects of the DA-SCZ connection?

At low doses catecholamines, such as DA, noradrenaline (NA) and adrenaline (A), are thought to protect nerve cells by virtue of their antioxidant activities; whereas, at high doses they are thought to be neurotoxic, acting as pro-oxidants [44]. The protective effect 
of DA, but not of NA and A, has been shown to be through the activation of DA D4 receptors [53]. It is also shown that DA D2 and/or D3 receptor activation protects neurons [54] and/or oligodendrocytes [55] against OS. Thus it is suggested that DA, through the activation of D2, D3 and/or D4 receptors, may protect cells from gradual changes in low levels of OS that occur in mild pathological insults and aging [53-55]. Therefore, it seems not implausible to suppose that increased DA transmission in the brain could occur as an adaptive process against OS, especially in the individuals with $\mathrm{MD}$ and resulting vulnerability to OS.

Indeed, it has been shown that in vitro and in vivo treatment with the mitochondrial complex I inhibitor rotenone enhances the sensitivity of striatal DA release to $\mathrm{OS}$ induced by $\mathrm{H}_{2} \mathrm{O}_{2}$ [56]. Thus, if MD and resultant vulnerability to OS underlie the pathophysiology of SCZ, positive symptoms of the disease might be explained as 'the price that the brain pays for its homeostasis at OS'.

\section{NMDA-R hypofunction theory of SCZ and the MGM}

$N$-methyl-D-aspartate-receptor (NMDA-R) antagonists, such as phencyclidine and ketamine, produce SCZ-like symptoms including negative symptoms and cognitive impairments in healthy individuals [57-59], and exacerbate both positive and negative symptoms in patients with chronic SCZ [60-62]. In addition, NMDA-R antagonists induce disinhibition of neurotransmitter systems through specific effects on inhibitory circuits [63]. These indirect observations have led to the NMDA-R hypofunction theory of SCZ $[42,64]$, which proposes that NMDA-R hypofunction provides a neuronal basis for the negative symptoms and cognitive impairments associated with SCZ and induce aberrations in the monoaminergic systems that could result in positive symptoms. Postmortem studies have revealed alterations in pre- and post-synaptic markers for glutamatergic neurons in several brain regions in patients with SCZ [64]. However, no conclusive evidence of NMDA-R hypofunction in SCZ has been obtained.

It has been shown that a rapid increase in ROS occurs in vitro [65] and in vivo [66] after exposure to NMDA-R antagonists. Exposure to ketamine suppresses the expression of GABAergic interneurons by inducing a persistent increase in brain superoxide through activation of $\mathrm{NADPH}$-oxidase in the prefrontal cortex [63]; thereby, causing increased excitatory neurotransmission. Thus, the evidence for NMDA-R hypofunction theory may also support the hypothesis that OS plays a central role in the pathophysiology of the symptoms associated with SCZ.

It should be noted that while excessive activation of NMDA-R triggers neuronal degeneration through intracellular OS and resulting MD [67], NMDA-R activation at subtoxic doses has a neuroprotective property due to brain-derived neurotrophic factor (BDNF) release [68-70] and/or blockade of c-Jun N-terminal kinase (JNK) activation [71]. NMDA-R has regulatory redox sites through which the oxidation status regulates the physiological activity of the receptors [72-75]. More recently it has been shown that trans-synaptic stimulation of NMDA-R boosts the class II antioxidant defenses by modifying the thioredoxin-peroxiredoxin system [76]. Thus, it would be conceivable that the brain, the highest energy consuming organ vulnerable to OS, has a third class of antioxidant defenses ('class III defenses') in which neurotransmissions are involved, and where transsynaptic activation of NMDA-R as well as DA- $R$ may occur, through unknown pre-synaptic redox regulation mechanisms, as an adaptive response to OS which could not be suppressed by the class I and II defenses. Failure to suppress OS by those three classes of antioxidant defenses may lead to persistent and strong OS and through suppressing the expression of inhibitory interneurons, may cause prolonged excessive glutamate and/ or DA release, leading to excitation toxicity and additional deterioration of the brain function (Figure 1).

\section{Enhanced carbonyl stress (CS) in SCZ and the MGM}

Recently Arai et al. [77] reported that a subset (47\%; $\mathrm{N}=21)$ of patients with SCZ $(\mathrm{N}=45)$ exhibit CS with high plasma pentosidine levels ( $>$ mean $+2 \mathrm{SDs}$ of controls), without underlying diabetes mellitus or chronic kidney disease, the two major causes of elevated AGEs (advanced glycation end-products). In addition, marked decreases in serum pyridoxal levels were found in 50\% $(\mathrm{N}=11)$ of those patients with CS. Since pyridoxal is a reactive carbonyl compounds (RCOs) scavenger, decreased pyridoxal levels may be due to the consumption of pyridoxal during prolonged CS. However, the molecular mechanisms underlying the CS in those patients remain unclear.

They also identified 2 rare frameshift variants of loss-of function type in GLO1 that encodes glyoxalase 1 (GLO1), a detoxifying enzyme of RCOs. While marked CS characterized by elevated AGEs and decreased pyridoxal was associated with those variants in patients with $\mathrm{SCZ}$, it was not in healthy controls. Then, how did these rare variants of GLO1cause CS only in patients with SCZ?

A number of enzymatic pathways including glyoxalase pathway contribute to the detoxification of RCOs, and redox coenzymes (reduced GSH and $\mathrm{NAD}(\mathrm{P}) \mathrm{H}$ ) are particularly important elements for the activity of these pathways [78]. On the other hand, it has been well known that OS increases RCOs production [78]. Therefore, enhanced OS and secondarily induced alteration of redox coenzyme homeostasis may cause CS in the affected population (Figure 1). And while these missense 


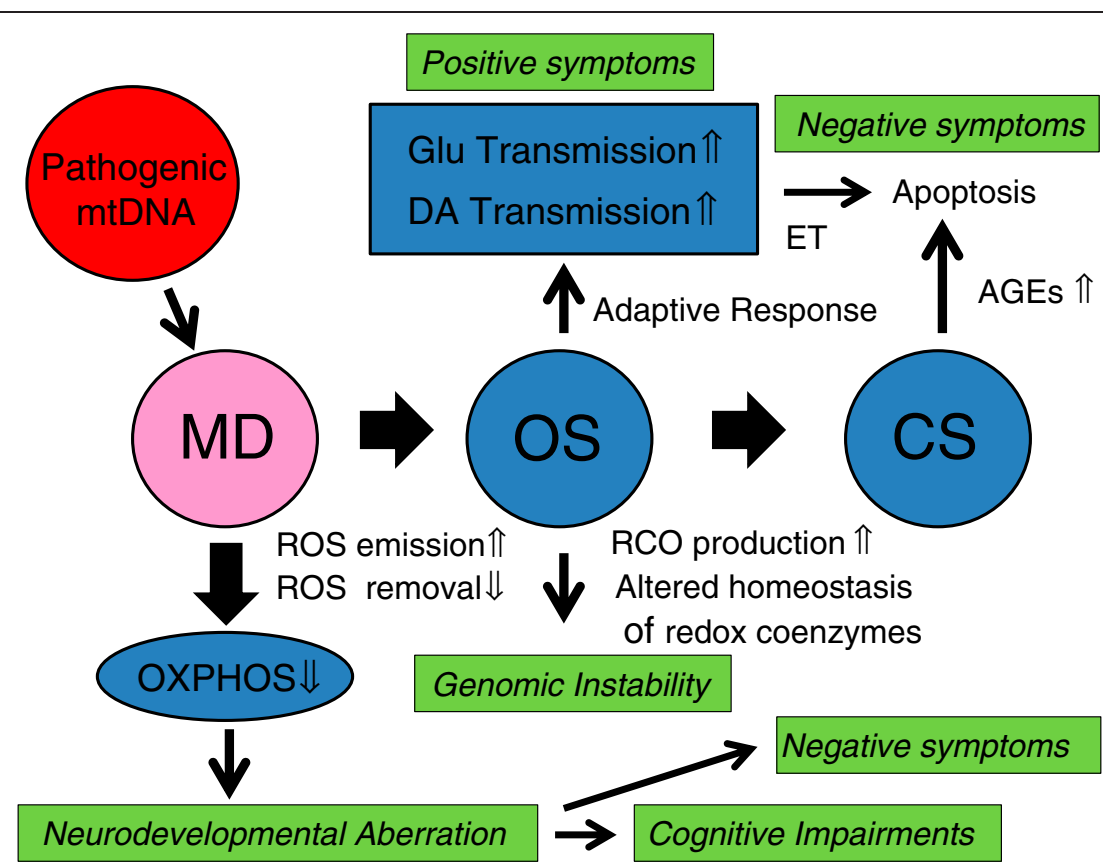

Figure 1 Proposed pathophysiology of schizophrenia. Mitochondrial dysfunction (MD), through imbalance of ROS production and removal, raises ROS emission, causing a strong intracellular OS. Disturbed OXPHOS and enhanced OS in predisposed individuals may cause various pathogenic alterations such as genomic instability, aberrations in neuromuscular development, brain dysfunction, and apoptosis. On the other hand, enhanced OS and secondarily induced alteration of redox coenzyme homeostasis may cause enhanced CS. It is assumed that the brain has the third class of antioxidant defenses in which neurotransmissions are involved, and that trans-synaptic activation of NMDA-R as well as DA-R may occur, through unknown pre-synaptic redox regulation mechanisms, as an adaptive response to OS which could not be suppressed by the class I (non-enzymatic) and II (enzymatic) defenses. Failure to suppress OS by those three classes of antioxidant defenses may lead to persistent strong OS and, through suppressing the expression of inhibitory interneurons, may cause prolonged excessive glutamate and/or DA release, leading to excitation toxicity (ET) and additional deterioration of the brain function.

variants in GLO1 may cause marked CS in patients with $\mathrm{SCZ}$, they may not cause CS in healthy controls because of normal redox coenzyme activities and lack of enhanced OS.

In this case, the rare frameshift variants of GLO1 detected by Arai et al. must be FGs. Indeed, patients carrying those rare variants have been severely affected and treatment-resistant cases while the frequency of those variants was not higher in patients with SCZ $(5 / 1761=0.28 \%)$ than in healthy controls $(10 / 1921=0.52 \%)[77]$.

\section{Predictions of the hypothesis}

This hypothesis predicts: (1) a higher maternal transmission of SCZ (H1), (2) positive associations between PGs and SCZ as well as negative associations between FGs and SCZ (H1), and (3) various pathogenic alterations such as genomic instability, aberrations in neuromuscular development, and brain dysfunction, that can be caused by disturbed OXPHOS and enhanced OS in predisposed individuals $(\mathbf{H 1}+\mathbf{H 2})$. In addition, the hypothesis predicts a possible therapeutic effect of ROS scavengers (H2).
Most of these predictions seem to be consistent with major epidemiological findings and the results of genetic studies to date.

\section{The mode of transmission}

The hypothesis (H1) predicts a higher maternal transmission. Although there has been no convincing evidence for an exclusively maternal transmission of SCZ, several reports suggest a higher maternal transmission of SCZ [79-82].

It also predicts that a certain proportion of patients are sporadic cases due to de novo mutation in the mtDNA. Given the average mutation rate in the mtDNA $\left(4.3 \times 10^{-3}\right)$ and the overall prevalence of SCZ $(\sim 0.7 \%)$, the expected proportion of de novo sporadic cases in the affected population is $\sim 0.6(=0.0043 / 0.007)$. This figure accords with the results of the epidemiological studies, and the fact that $60 \%$ of patients with SCZ have no affected first- and second-degree relatives [1].

Some researchers have hypothesised that SCZ is associated with de novo mutations arising in paternal germ cells [83-87]. This is based on the observation 
('paternal age effect') that the risk of SCZ in the offspring seems to increase as the paternal age advances from 20 years to over 50 years. However, the difference in the mean age of fathers of affected and unaffected individuals is not very large $(<1.7$ years $)$ $[83,86]$. Furthermore, there has always been increased risk of SCZ for the offspring of younger men $(<21$ years) $[83,86,87]$ and younger women $(<20$ years $)$ [86] Therefore, major roles of paternally derived mutations in SCZ seem to remain unsubstantiated. Indeed, no available data can exclude the possibility that the 'paternal age effect' has a 'maternal origin'; while women in many countries today may be expected to bear children after the age of 20 years and not to marry much older or younger men unless the men have special socio-economic benefits, a certain proportion of women genetically predisposed to SCZ might behave differently.

It should be noted that in the famous twin study by Gottesman and Bertelsen [88] that included almost equal numbers of male and female monozygotic twins discordant for SCZ, most schizophrenic twins whose offspring were affected were females (12 out of 14), implying that the transmission was mainly via females $\left(P={ }_{14} C_{12} \times\right.$ $\left.0.5^{14}+{ }_{14} C_{13} \times 0.5^{14}+{ }_{14} C_{14} \times 0.5^{14}<0.007\right)$.

\section{Every SCZ-associated gene is either a PG for SCZ or a PG- linked gene}

In the MGM, G-G interactions between the nuclear genome and the pathogenic mitochondrial genome give rise to SCZ-associated PGs that decrease the risk and the severity of SCZ. Thus, the hypothesis (H1) predicts that every SCZ-associated gene is either a PG for SCZ or a PG-linked gene.

Cys 311 of DRD2 polymorphism and 'high risk' variants of NRG1, DTNBP1, and NPY may be such examples because schizophrenics carrying those variants exhibit less negative symptoms [89-91]. Unfortunately, most association studies to date lack sufficient clinical data about the onset and the clinical symptoms of subjects to determine the nature of the SCZ-associated variants detected.

\section{An apparent signature of positive selection in SCZ- associated genes}

Since the positive selection of the SCZ-associated alleles (= protective alleles) mentioned above occurs only in the predisposed matrilineal pedigrees, a ubiquitous subpopulation in humans, frequencies of those alleles may not be as high as if the selection had occurred recently in the general population. Thus the hypothesis (H1) predicts that every SCZ-associated nuclear gene has an apparent signature as if it has been subject to positive selection in the recent evolutionary history of humans.
Two recently published reports [92,93] seem to concur with this prediction. On the other hand, the NGM predicts that every SCZ-associated nuclear gene has an apparent negative selection signature due to the strong negative selection pressure, which is contrary to these reports.

\section{Sex differences and the protective effect of estrogen in SCZ}

The hypothesis (H2) predicts that endogenous antioxidants exhibit a protective effect against SCZ, and may give a plausible explanation for sex differences in the disease.

A consistent and specific finding for SCZ is that the age at onset is significantly lower in males than in females $[1,94]$. SCZ starts earlier on average in males and reaches its peak between 15 and 25 years of age; whereas, in females it occurs almost between 20 and 30 years of age and shows a less steep curve after that age. It also appears that women are vulnerable to relapses or first episodes of SCZ in the perimenoposal period (the second peak of onset for females) [94], when estrogen production diminishes. A close association between premenstrual or menstruation phase and exacerbation of the illness in females has been well documented [94]. In addition, less negative symptoms, less brain morphological changes, and a better response to neuroleptics are relatively consistent findings in female patients with SCZ [95].

From these observations, one may infer that estrogen protects predisposed females [94]. However, the exact mechanism for this finding remains unclear [94,95]. The hypothesis (H2) may provide a plausible explanation, because estrogen has been shown to exhibit antioxidant activity due to its intrinsic antioxidant structure that lies in the phenolic moiety of the steroidal compound [96], to increase antioxidant enzyme activities [97,98], and to have a neuroprotective effect against OS [96,99]. Furthermore, mitochondrion has estrogen binding sites [100,101] and estrogen increases mitochondrial efficiency and reduces intracellular OS [102].

\section{Prenatal risk factors for SCZ}

The hypothesis (H2) predicts that early-life exposure to environments that induce OS can increase the risk of later development of SCZ in the predisposed population.

Indeed, prenatal environmental factors such as severe nutritional deficiency [103], exposure to increased homocysteine [104] or lead [105], and infection of influenza virus [105-107] and Toxoplasma gondii [108] have been suggested to increase the risk for SCZ. More recently, it has been suggested that central nervous system infections of cytomegalovirus or mumps virus in childhood may also increase the risk for SCZ [109]. All of these factors have been shown to affect mitochondria, inducing strong intracellular OS and/or apoptosis [110-122]. 


\section{Increased obstetric complications in the birth of patients with SCZ}

It has been suggested that MD may be involved in the etiology of preeclampsia [123-125]. Furthermore, a high incidence of preeclampsia, eclampsia, and stillborn infants has been observed in a family with a known mitochondrial disorder [126]. Folgero et al. [127] demonstrated two separate mtDNA point mutations in two families having a high incidence of preeclampsia and eclampsia.

Therefore, the hypothesis (H1) predicts that the risk of preeclampsia and stillbirth may be increased in the birth of patients with SCZ as well as in the pregnancies of women with SCZ.

There has been a body of evidence used to account for an increased risk of obstetric complications (OCs) in the birth of patients with SCZ [128,129]. A meta-analysis of population-based data [129] found significant estimates for three main categories of OCs: (1) complications of pregnancies, (2) abnormal fetal growth and development, and (3) complications in delivery. Among all, preeclampsia was the strongest individual risk factor detected in the largest single population-based cohort study to date [128]. Although obstetrical events in SCZ are often considered as having a direct causative effect, no available data have been able to refute the theory that these events are merely markers of some other causal process [130], such as MD implicated in this hypothesis (H1). An excess of stillbirths and neonatal deaths among women with SCZ has been reported by several investigators [131-133].

\section{Low comorbidity between SCZ and rheumatoid arthritis (RA)}

The hypothesis (H1) predicts that diseases predisposed by FGs, if present, would be negatively associated with $S C Z$. RA could be one such candidate.

OS plays a role in the pathogenesis of RA (for review, see [134]). In addition, it has been shown that chronic OS in the synovial $\mathrm{T}$ lymphocytes is not secondary to exposure to environmental ROS, but instead originates from intracellularly produced ROS [135]. Therefore, a presumed susceptibility gene for RA that may cause intracellular OS in several cell lines could be a FG for SCZ in the MGM, and is likely negatively associated with SCZ.

Indeed, robust evidence shows a negative association between SCZ and RA; although, the exact mechanism is unknown [1,136-138]. According to the NGM, several hypotheses have been proposed, including that pathogenic genes for SCZ may be protective genes for RA and vice versa [1,136-138].

Thus the MGM may offer a new explanation for the low comorbidity and provide an additional prediction: most of patients with both of SCZ and RA would be females because the survival rate of males in early life stages must be remarkably reduced due to lack of protection by estrogen, and show more negative symptoms, poorer response to neuroleptic medication, and/ or more pronounced morphological changes in the brain.

\section{Genomic or epigenomic instability}

It has been shown that endogenous mitochondrial OS can induce many types of DNA damage including double strand breaks, end-to-end fusions, base and sugar modifications, DNA-protein cross-links, and gross chromosomal rearrangements $[139,140]$. Therefore, the hypothesis (H1) predicts that the enhanced OS may cause genomic or epigenomic instability during meiosis and/or early phase of ontogeny, producing increased rates of random point mutations and/or structural variants of the nuclear genome in the affected population. In addition, genomic instability may be more pronounced in male patients due to lack of antioxidant protection by estrogen.

There have been numerous reports of associations between SCZ and chromosomal abnormalities including fragile sites, reciprocal translocations, inversions, insertions, deletions, disomy and trisomy in many autosomes, and sex chromosome aneuploidies [141]. However, with the exception of 22q11 deletion, none of these have been consistently replicated.

A popular explanation in the NGM may be that most of these structural variants are coincidental findings of no clinical significance. Alternatively, those alterations may indicate genomic instability in SCZ. An increased risk of SCZ in individuals with 22q11 deletion [142,143] might be due to haplodeficiency of presumptive PGs of gain-offunction type and/or presumptive FGs of loss-of-function type aggregated on 22q11.

More recently, it has been reported that rare structural variants such as microdeletions or microduplications of sizes ranging from $100 \mathrm{~kb}$ to $15 \mathrm{MB}$ throughout the genome are more frequent among individuals with SCZ than unaffected individuals [144]. While many of those structural variants duplicate or delete genes in neurodevelopmental pathways, one third of those do not disrupt genes, leaving their role in causation of the disease unwarranted. Another recent report [145] has shown that de novo copy number mutations are increased in sporadic SCZ. However, the cytobands of those copy number mutations are diverse among the affected individuals and their roles in the pathogenesis still remain unclear. Therefore, no available data can refute the possibility that those structural variants and copy number mutations are not the cause of SCZ but the results of the genomic instability in SCZ predicted by our hypothesis.

Indeed, direct measure of the de novo mutation rates shows an increased mutation rate in SCZ [146], 
and genomic or epigenomic instability has been suggested in SCZ [147]. Furthermore, it has been shown that blood cells from patients with SCZ present a higher rate of folate-sensitive fragile sites, and that male patients exhibit twice as many fragile sites as females while there are no age effects [148]. This sex difference may indicate that increased fragile sites expression (genomic instability) is the results of enhanced OS associated with SCZ.

\section{Inconsistency in the results of the association studies on the} nuclear genome

Results of association studies based on the NGM have been inconsistent, and SCZ-associated genes including copy number variations differ across populations or even across individuals of the same ethnicity $[19,20,144,145]$.

The only plausible explanation for this inconsistency in the NGM is that there is an extreme heterogeneity in the genetic basis of SCZ.

On the other hand, these perplexing results of the association studies to date accord with a specific prediction of the hypothesis: in the MGM, a disease-associated allele is likely to be a PG, and may show a stronger association with milder cases and unaffected siblings but not with severe cases, while a negatively associated allele is likely to be a FG, and may show a positive association with severer early-onset cases. Therefore, an association detected in a study with mildly affected subjects may not be supported in studies with severely affected subjects, and an association detected in a study with severely affected subjects may not be supported in studies with mildly affected subjects. This is a specific prediction of the hypothesis (H1).

\section{Therapeutic effects of ROS scavengers}

In this hypothesis $(\mathbf{H} \mathbf{1}+\mathbf{H} \mathbf{2}), \mathrm{OS}$ and secondarily induced CS cause pathogenic alterations in SCZ. Therefore, it predicts that ROS scavengers have therapeutic effects on $S C Z$.

Indeed, adjuvant therapy using neuroleptics and antioxidants such as omega-3 poly unsaturated fatty acids, ascorbic acid, $\alpha$-tocopherol or $\mathrm{N}$-acetyl cysteine have been shown to improve clinical outcomes of patients with SCZ (for review see [18]). However, the most promising therapeutic antioxidant for SCZ may be molecular hydrogen, which rapidly diffuses across membranes and selectively reacts with cytotoxic ROS, but not with other ROS that play physiological roles [149]. This prediction can be easily tested in the near future.

\section{Possibilities and limitations of the hypothesis}

This new hypothesis seems to explain various and specific aspects of $\mathrm{SCZ}$ and somewhat perplexing results of association studies to date. It meets the four criteria for evolutionary hypotheses of SCZ proposed by Brüne [4] because it: (1) provides a convincing mechanism for the preservation of genes in the human gene pool associated with SCZ, (2) explains potential sex differences, (3) accounts for the multifaceted symptomatology, and (4) is consistent with neuropsychological, developmental and evolutionary findings regarding the human brain.

However, there are several limitations to this hypothesis. First of all, it is only a theory that lacks direct and compelling evidence. Especially, the assumption of the class III antioxidant defenses in the brain should be tested in neurophysiological studies in the future. Second, the exact mechanism of discordance in monozygotic twins remains unclear. Although the hypothesis may explain the discordance due to different mutation loads in the first ovum cleavage, it still requires future investigation. Third, while there have been several studies that report new variants in the mitochondrial genome associated with SCZ [150-156], there have been no consistent findings on the pathogenic variants in the mitochondrial genome. However, it should be noted that any missense variant in the mitochondrial genome can be a pathogenic genome in the MGM because it may contribute to cause disturbed OXPHOS and enhanced OS. There could be heterogeneity in the genetic basis of SCZ in the MGM, as are the cases with known mitochondrial diseases [157].

Although a recent study failed to detect any pathogenic mitochondrial genome in the blood cells [158], it cannot necessarily deny the possibility of the MGM because of the heteroplasmy of the mitochondrial genome. It has been well known that pathogenic mitochondrial genome cannot necessarily be detected in the blood cells in known mitochondrial diseases [159]. Therefore, other cell lines such as muscles, neurons, or hair follicles should be examined to detect pathogenic variants in the mitochondrial genome in the future.

\section{Conclusions}

Genetic research of SCZ based on the NGM has been one of the most active areas in psychiatry for the past two decades. Although this effort is ongoing, results of association studies based on the NGM have been disappointing, or rather perplexing. No particular susceptibility gene that accounts for a large proportion of heritability has been identified by association studies. The results of association studies have been inconsistent, and SCZ-associated variants including copy number variations differ across populations or even across individuals of the same ethnicity.

The central paradox of SCZ genetics and the results of association studies to date argue against the NGM 
for SCZ today, and in its place the MGM is emerging as a viable option to account for genomic and pathophysiological research findings involving this enigmatic disorder.

\section{Appendix A. Deduction of the persistence criterion}

Deduction of the P-criterion is explained in detail elsewhere [11]. Therefore, we present here the essence of the method. At first we describe our three basic assumptions.

\section{An ideal human population}

We assume here a random-mating human population with a sufficiently large effective population size at equilibrium, where negative selection pressures on the susceptibility alleles for SCZ are predominant and the effect of genetic drift is negligibly small. The prevalence $p$ of $\mathrm{SCZ}$ in this ideal human population is assumed to be stable across generations by mutation-selection balance. Therefore, the gene frequency in the general population $\left(m_{G}\right)$ is given in terms of the gene frequencies in the affected population $\left(m_{A}\right)$ and in the unaffected population $\left(m_{U}\right)$ :

$$
\begin{aligned}
& m_{G}=p m_{A}+(1-p) m_{U}, \text { or } \\
& m_{A}-m_{G}=(1-p) d .\left(d \equiv m_{A}-m_{U}\right)
\end{aligned}
$$

\section{Mutation-selection balance in each risk locus}

We assume here that the total number of population frequencies of the pathogenic alleles at each risk locus is preserved by mutation-selection balance. Therefore, $-\Delta m_{G}$, the cross-generational reduction in the frequency of a pathogenic allele should not be more than the rate of mutations that produce pathogenic variants at the locus. On the other hand, since mutations at the locus include mutations of two directions that produce pathogenic or non-pathogenic variants, the mutation rate at the locus should be greater than the rate of mutations that produce pathogenic variants at the locus. Thus we have:

$$
\mu>-\Delta m_{G}
$$

\section{Multifactorial threshold model}

We assume the multifactorial threshold model, in which quantitative traits such as liability to the disease are determined by multiple genetic and non-genetic factors including a stochastic and/or an epigenetic effect. Under this assumption, the relative fitness as a quantitative trait in the affected population is determined by multiple factors and approximately follows a gamma distribution with a mean $(1-s)$. ( $s$ is the selection coefficient of SCZ; the mean relative fitness in the normal population is defined as unity.)

The distribution curve of the fitness in the affected subpopulation with a SCZ-associated allele $\mathrm{M}$ never shifts to the right unless $M$ has a strong protective effect (i.e. the effect of elevating reproductive fitness by reducing severity of and liability to the disease). Therefore, we can assume that $s_{M}$, the selection coefficient in the affected subpopulation with a SCZ-associated allele $M$, is not smaller than $s\left(s \leq s_{M}<1\right)$ for a susceptibility allele. The inequality $s>s_{M}$ implies that $\mathrm{M}$ is a protective gene that reduces the severity and the risk of the disease.

No special assumptions are required on the allelic structure in each locus, or penetrance of each susceptibility gene, and possible interactions among the loci.

Now we proceed to deduce the persistence criteria. From the assumptions, $m^{\prime}{ }_{G}$, the population frequency of the SCZ-associated allele $\mathrm{M}$ in the next generation, is given by: $m_{G}^{\prime}=\frac{p \cdot m_{A} \cdot\left(1-s_{A}\right)+(1-p) \cdot m_{U} \cdot 1}{p \cdot\left(1-s_{M}\right)+(1-p) \cdot 1}=\frac{m_{G}-s_{M} p m_{A}}{1-s_{M} p}$. Therefore, from (A1), the reduction of the population frequency of the SCZ-associated allele $M$ per generation is

$$
\begin{aligned}
-\Delta m_{G} & =m_{G}-m_{G}^{\prime}=\frac{s_{M} p\left(m_{A}-m_{G}\right)}{1-s_{M} p} \\
& =p(1-p) d \cdot \frac{s_{M}}{1-s_{M} p} .
\end{aligned}
$$

From (A2) and (A3) we have

$$
\mu>p(1-p) d \cdot \frac{s_{M}}{1-s_{M} p} .
$$

Since $\frac{s_{M}}{1-s_{M} p}$ is monotonically increasing for $s_{M}\left(0<s_{M}\right.$ $<1$ ) and $s \leq s_{M}<1$ holds for susceptibility allele $\mathrm{M}$, we have

$$
\mu>p(1-p) d \cdot \frac{s}{1-s p}, \text { or } \frac{(1-s p) \mu}{(1-p) s p}>d
$$

Thus we have the criterion for a susceptibility gene:

$$
d<v
$$

where $v$ is defined as $v \equiv \frac{(1-s p) \mu}{(1-p) s p}$.

From the observation (A5), we can see that $d \geq v$ implies $s>s_{M}$ for any SCZ-associated variant $\mathrm{M}$ which is sustained by mutation-selection balance.

\section{Appendix B. Mutation rates and parameter- estimations for $S C Z$}

Mutation rates on autosomes and the $\mathrm{X}$ chromosome almost always fall within the range between $10^{-6}$ and $10^{-4}$ per locus per generation (usually $<10^{-5}$; one generation $=20$ years $)[13,14]$ and can be approximated by a linear function of the parental age at least under 
30 years for maternal age and under 40 years for paternal age [160]. Large-sampled cohort studies in Israel, Sweden and Denmark show that the mean age of parents in the general population is $\sim 28$ years for mothers and 31 years for fathers; the mean age of both parents is $<29.6$ years $[83,86]$. Therefore we can assume: $10^{-6}<$ $\mu<\frac{29.6}{20} \times 10^{-4}=1.48 \times 10^{-4}$.

According to the epidemiological data by Haukka et al. [8], the estimated values for $p$ and $s$ are $p=1.29 \times 10^{-2}$ and $s=6.54 \times 10^{-1}$. Therefore, we have $v=1.76 \times$ $10^{-3}$ for the average mutation rate $\left(1.48 \times 10^{-5}\right), v=$ $1.76 \times 10^{-2}$ for the highest mutation rate $\left(1.48 \times 10^{-4}\right)$, and $v=1.76 \times 10^{-4}$ for a relatively low mutation rate $\left(1.48 \times 10^{-6}\right)$.

\section{Appendix C. Estimation of the required sample size of a GWAS}

Concerning the required sample size $2 N$ ( $N$ case-control pairs) and the power $1-\beta$ of an association study, we have the well-established formula [161]:

$$
N \cong \frac{1}{2}\left(\frac{z *_{\alpha} \sqrt{2 \times(1-x)}+z_{\beta} Y}{d}\right)^{2} \text {, where } x \text { (population fre- }
$$

quency of the allele), $d$ (case-control difference of allele frequencies) and $\gamma^{2}$ are defined as: $x \equiv \frac{1}{2}\left(m_{A}+m_{U}\right)$, $d \equiv m_{A}-m_{U}$, and $\gamma^{2} \equiv m_{A}\left(1-m_{A}\right)+m_{U}\left(1-m_{U}\right)=$ $2 x(1-x)-\frac{1}{2} d^{2}$.

For the average mutation rate $\mu=1.48 \times 10^{-5}$, we have $v=1.76 \times 10^{-3}$. Supposing $0.0005<x<0.9995$, we have $2 x(1-x)>0.9995 \times 10^{-3}$. From the persistence criterion, we have: $\frac{1}{2} d^{2}<\frac{1}{2} v^{2}<1.6 \times 10^{-6}<$ $2 x(1-x) \times 0.002$. Therefore, we have the following approximation with an error smaller than $0.2 \%$ :

$$
\begin{aligned}
& \gamma^{2}=2 x(1-x)-\frac{1}{2} d^{2} \cong 2 x(1-x), \text { or } \\
& \gamma \cong \sqrt{2 x(1-x)} .
\end{aligned}
$$

Thus, we have $N \cong \frac{1}{2}\left(\frac{z_{\alpha} \sqrt{2 x(1-x)}+z_{\beta} \gamma}{d}\right)^{2} \cong\left(\frac{z *_{\alpha}+z_{\beta}}{d}\right)^{2}$ $x(1-x)>\left(\frac{z *_{\alpha}+z_{\beta}}{v}\right)^{2} x(1-x)$.

Let us calculate the required sample size in a GWAS $\left(\alpha=2.5 \times 10^{-7}, 1-\beta=0.80\right)$. Since we have $z *_{0.00000025}+$ $z_{0.2}=5.99$,

$$
N>\left(\frac{z_{\alpha}^{*}+z_{\beta}}{v}\right)^{2} x(1-x)=\left(\frac{5.99}{1.76 \times 10^{-3}}\right)^{2} x(1-x)=2.90 \times
$$

$10^{6}$ for $x=0.5$. Therefore, more than 2.9 million case- control pairs are required in a genome-wide association study with a power of 0.8 to detect a susceptibility variant of the average mutation rate and a population frequency between 0.0005 and 0.9995 .

Similarly we can see that more than 29,000 case-control pairs are required in a genome-wide association study with a power of 0.8 to detect a susceptibility variant of the highest mutation rate $\left(\mu=1.48 \times 10^{-4}\right)$ and a population frequency between 0.005 and 0.995 .

Finally, let us consider the case with a relatively low mutation rate $\mu=1.48 \times 10^{-6}$, which corresponds to $v=1.76 \times 10^{-4}$. In this case, more than 290 million case-control pairs are required in a GWAS with a power of 0.8 to detect a susceptibility variant of a population frequency between 0.000005 and 0.999995 .

\section{Abbreviations}

AGEs: Advanced glycation endproducts; CS: Carbonyl stress; DA: Dopamine; DA-R: Dopamine receptor; DRD2: Dopamine D2 receptor; ET: Excitation toxicity; FG: Facilitating gene that increases the risk and the severity of schizophrenia in the presence of a pathogenic mitochondrial genome; G-E interaction: Gene-environment interaction; G-G interaction: Gene-gene interaction; Glu: Glutamate; GSH: Glutathione; GWAS: Genome-wide association study; MD: Mitochondrial dysfunction; MGM: Mitochondrial genome model; mtDNA: Mitochondrial DNA; NADH: Reduced nicotinamide adenine dinucleotide; NADPH: Reduced nicotinamide adenine dinucleotide phosphate; ncDNA: Nuclear DNA; NGM: Nuclear genome model; NMDA-R: Nmethyl-D-aspartate-receptor; OR: Odds ratio; OS: Oxidative stress;

OXPHOS: Oxidative phosphorylation; PG: Protective gene that decreases the risk and the severity of schizophrenia; ROS: Reactive oxygen species; RCO: Reactive carbonyl compound; rRNA: Ribosomal RNA; tRNA: Transfer RNA; SCZ: Schizophrenia; $Z^{*}{ }_{a}$ : The two sided a point of the standard normal curve; $Z_{\beta}$ : The upper $\beta$ point of the standard normal curve.

\section{Competing interest}

We declare no conflict of interest.

\section{Authors' contribution}

ND and YH conceived the study and wrote the first draft. YH, MI, TY, TI, MA, $\mathrm{CU}$ and $\mathrm{HT}$ revised the manuscript through discussion with ND. All authors read and approve the final manuscript.

\section{Author details}

${ }^{1}$ Ibaraki Prefectural Medical Center of Psychiatry, 654Asahi-machi, Kasama-shi, Ibaraki 309-1717, Japan. ${ }^{2}$ Integrated Neuroscience Research Project, Tokyo Metropolitan Institute of Medical Science, 2-1-6 Kamikitazawa, Setagaya, Tokyo 156-8506, Japan. ${ }^{3}$ Project for Schizophrenia and Affective Disorders Research, Tokyo Metropolitan Institute of Medical Science, 2-1-6 Kamikitazawa, Setagaya, Tokyo 156-8506, Japan. ${ }^{4}$ Laboratory for Molecular Psychiatry, RIKEN Brain Science Institute, 2-1Hirosawa, Wako-shi, Saitama 351-0198, Japan. ${ }^{5}$ Department of Psychiatry, Juntendo University Nerima Hospital, 3-1-10 Takanodai, Nerima-ku, Tokyo 177-8521, Japan. ${ }^{6}$ Department of Psychiatry, Graduate School of Comprehensive Human Science, Tsukuba University, Tsukuba-shi, Ibaraki, Japan.

Received: 18 November 2011 Accepted: 27 April 2012 Published: 31 May 2012

\section{References}

1. Jablensky AV: Schizophrenia: the Epidemiological Horizon. In Schizophrenia. Edited by Hirsch SR, Weinberger DR. London: Blackwell Science; 1995:206-252.

2. Huxley J, Mayr E, Osmond H, Hoffer A: Schizophrenia as a genetic morphism. Nature 1964, 204:220-221.

3. Crow TJ: A Darwinian approach to the origin of psychosis. Brit J Psychiatry 1995, 167:12-25 
4. Brüne M: Schizophrenia - an evolutionary enigma? Neurosci Biobehav Rev 2004, 28:41-53.

5. Keller CK, Miller G: Resolving the paradox of common, harmful, heritable mental disorders: Which evolutionary genetic models work best? Behav Brain Sci 2006, 29:385-452.

6. Bassett AS, Bury A, Hodgkinson KA, Honer WG: Reproductive fitness in familial schizophrenia. Schizophr Res 1996, 21:151-160.

7. McGrath JJ, Hearle J, Jenner L, Plant K, Drummond A, Barkla JM: The fertility and fecundity of patients with psychoses. Acta Psychiatr Scand 1999, 99:441-446.

8. Haukka J, Suvisaari J, Lonnqvist J: Fertility of patients with schizophrenia, their siblings, and the general population: a cohort study from 1950 to 1959 in Finland. Am J Psychiatry 2003, 160:460-463.

9. Svensson AC, Lichtenstein P, Sandin S, Hultman CM: Fertility of first-degree relatives of patients with schizophrenia: $A$ three generation perspective. Schizophr Res 2007, 91:238-245.

10. Bundy $\mathrm{H}$, Stahl D, McCabe $\mathrm{JH}$ : A systemic review and meta-analysis of the fertility of patients with schizophrenia and their unaffected relatives. Acta Psychiatr Scand 2011, 123:98-106.

11. Doi N, Hoshi Y, Itokawa M, Usui C, Yoshikawa T, Tachikawa H: Persistence criteria for susceptibility genes for schizophrenia - a discussion from an evolutionary view point. PLoS One 2009, 4(11):e7799.

12. Sigurđardóttir S, Helgason A, Gulcher JR, Stefansson K, Donnely P: The mutation rate in the human mtDNA control region. Am J Hum Genet 2000, 66:1599-1609.

13. Vogel F, Motulsky AG: Human genetics: problems and approaches. Berlin: Springer; 1997.

14. Nachman MW, Crowell SL: Estimate of the mutation rate per nucleotide in humans. Genetics 2000, 156:297-304.

15. Marchbanks RM, Mulcrone J, Whatley SA: Aspects of oxidative metabolism in schizophrenia. Brit J Psychiatry 1995, 167:293-298.

16. Ben-Shachar D: Mitochondrial dysfunction in schizophrenia: a possible linkage to dopamine. J Neurochemistry 2002, 83:1241-1251.

17. Wood SJ, Yücel M, Pantelis C, Berk M: Neurobiology of schizophrenia spectrum disorders: the role of oxidative stress. Ann Acad Med Singapore 2009, 2009(38):396-401.

18. Bitanihirwe BKY, Woo TUW: Oxidative stress in schizophrenia: an integrated approach. Neurosci Biobehav Rev 2011, 35:878-893.

19. Allen NC, Bagade S, McQueen MB, loannidis JP, Kavvoura FK, Khoury MJ, Tanzi RE, Bertram L: Systematic meta-analyses and field synopsis of genetic association studies in schizophrenia: the szgene database. Nat Genet 2008, 40:827-834 [http://www.schizophreniaforum.org/res/szgene/ default.asp]

20. Need AC, Ge D, Weale ME, Maia J, Feng S, Heinzen EL, Shianna KV, Yoon W, Kasperaviciūte D, Gennarelli M, Strittmatter WJ, Bonvicini C, Rossi G, Jayathilake K, Cola PA, McEvoy JP, Keefe RS, Fisher EM, St Jean PL, Giegling I, Hartmann AM, Möller HJ, Ruppert A, Fraser G, Crombie C, Middleton LT, St Clair D, Roses AD, Muglia P, Francks C, Rujescu D, Meltzer HY, Goldstein DB: A genome-wide investigation of SNPs and CNVs in schizophrenia. PLOS Genet 2009, 5(2):e1000373.

21. U.S. Census Bureau: World POPClock Projection. [http://www.census.gov/ population/popclockworld.html]

22. Saha S, Chant D, Welham J, McGrath J: A systemic review of the prevalence of schizophrenia. PLoS Med 2005, 2:413-433.

23. Andreyev AY, Kushnareva YE, Starkov AA: Mitochondrial metabolism of reactive oxygen species. Biochemistry (Moscow) 2005, 70:200-214.

24. Esposito LA, Melov S, Panov A, Cottrell BA, Wallace DC: Mitochondrial disease in mouse results in increased oxidative stress. Proc Natl Acad SCi USA 1999, 96:4820-4825.

25. Senoo-Matsuda N, Yasuda K, Tsuda M, Ohkubo T, Yoshimura S, Nakazawa H, Hartman PS, Ishii N: A defect in the cytochrome b large subunit in complex II causes both superoxide anion overproduction and abnormal energy metabolism in Caenorhabditis elegans. J Biol Chem 2001, 276:41553-4155819.

26. Hayashi M: A study on schizophrenia. Psychiatr Neurol Japonica 1950 51:193-253.

27. Utena H, Ezoe T: Studies on the carbohydrate metabolism in brain tissues of schizophrenic patients. II. Report. Psychiatr Neurol Japonica 1951, 52:216-233.

28. Takahashi Y: An enzymological study on brain tissue of schizophrenic patients. Carbohydrate metabolism. Folia Psychiatr Neurol Jpn 1953, 7:214-269.
29. Stabeneau JR, Pullin W, Moshe RLR, Froman C, Friedhoff AJ, Turner W: Study of monozygotic twins discordant for schizophrenia. Some biologic variables. Arch Gen Psychiatry 1969, 20:145-158.

30. Prabakaran S, Swatton JE, Ryan MM, Huffaker SJ, Huang JT, Griffin JL, Wayland M, Freeman T, Dudbridge F, Lilley KS, Karp NA, Hester S, Tkachev D, Mimmack ML, Yolken RH, Webster MJ, Torrey EF, Bahn S: Mitochondrial dysfunction in schizophrenia: evidence for compromised brain metabolism and oxidative stress. Mol Psychiatry 2004, 9:684-697.

31. Arieti S: Heredity and constitution in schizophrenia. In Interpretation of Schizophrenia. London: Jason Aronson Inc; 1974:441-451.

32. Meltzer HY, Moline R: Muscle abnormalities in acute psychosis. Arch Gen Psychiatry 1970, 23:481-491.

33. Meltzer HY: Neuromuscular dysfunction in schizophrenia. Schizophr Bull 1976, 2:107-135.

34. Fish B: Neurobiologic antecedents of schizophrenia in children. Arch Gen Psychiatry 1977, 34:1113-1118.

35. Cantor S, Trevenen C, Postuma R, Dueck R, Fjeldsted B: Is childhood schizophrenia a cholinergic disease? Arch Gen Psychiatry 1980, 37:658-667.

36. Flyckt L, Borg J, Borg K, Ansved T, Edman G, Bjerkenstedt L, Wiesel FA: Muscle biopsy, macro EMG, and clinical characteristics in patients with schizophrenia. Biol Psychiatry 2000, 47:991-999.

37. Kato T: The other, forgotten genome: mitochondrial DNA and mental disorders. Mol Psychiatry 2001, 6:625-633.

38. Fattal O, Budur K, Vaughan AJ, Franco K: Review of the literature on major mental disorders in adult patients with mitochondrial diseases. Psychosomatics 2006, 47:1-7.

39. Roubertoux PL, Sluyter F, Carlier M, Marcet B, Maarouf-Veray F, Chérif C, Marican C, Arrechi P, Godin F, Jamon M, Verrier B, Cohen-Salmon C: Mitochondrial DNA modifies cognition in interaction with the nuclear genome and age in mice. Nat Genet 2003, 35:65-69.

40. Seeman P: Dopamine receptors and the dopamine hypothesis of schizophrenia. Synapse 1987, 1:133-152.

41. Carlsson A: The current status of the dopamine hypothesis of schizophrenia. Neuropsychopharmacology 1988, 1:179-186.

42. Carlsson A, Hansson LO, Warters N, Carlsson ML: A glutamatergic deficiency model of schizophrenia. Br J Psychiatry 1999, 37(Suppl):2-6.

43. Laruelle M, Abi-Dargham A, Gil R, Kegeles L, Innis R: Increased dopamine transmission in schizophrenia: relationship to illness phase. Biol Psychiatry 1999, 46:56-72.

44. Noh JS, Kim EY, Kang JS, Kim HR, Oh YJ, Gwag BJ: Neurotoxic and neuroprotective actions of catecholamines in cortical neurons. Exp Neurol 1999, 159:217-224

45. Friedhoff AJ: A dopamine-dependent restitutive system for the maintenance of mental normalcy. Ann NY Acad Sci 1986, 463:47-52.

46. Davila R, Zumarraga M, Friedhoff AJ, Miller JC: Characteristics of the adaptive aspects of the dopamine system. Psychopharmacol Bull 1988, 24:338-340.

47. Friedhoff AJ, Simkowvitz P: A new conception of the relationship between psychological coping mechanisms and biological stress buffering systems. Br J Psychiatry 1989, 154(Suppl 4):61-66.

48. Bowers MB Jr, Swigar ME, Jatlow PI, Goicoechea N: Plasma catecholamine metabolites and early response to haloperidol. J Clin Psychiatry 1984 45:248-251.

49. Picker D, Labarca R: Neuroleptic-induced decrease in plasma homovanillic acid and antipsychotic activity in schizophrenic patients. Science 1984 225:954-957.

50. Bowers MB Jr, Swigar ME, Jatlow PI, Hoffman FJ: Plasma catecholamine metabolites and treatment response at neuroleptic steady state. Biol Psychiatry 1989, 25:734-738.

51. Arinami T, Itokawa M, Enguchi H, Tagaya H, Yano S, Shimizu H, Hamaguch $H$, Toru M: Association of dopamine D2 receptor molecular variant with schizophrenia. Lancet 1994, 343(8899):703-704.

52. Itokawa M, Toru M, Ito K, Tsuga H, Kameyama K, Haga T, Arinami T, Hamaguchi $\mathrm{H}$ : Sequestration of the short and long isoforms of Dopamine D2 receptors expressed in Chinese hamster ovary cells. Mol Pharmacology 1996, 49:560-566.

53. Ishige K, Chen Q, Sagara Y, Schubert D: The activation of dopamine D4 receptors inhibit oxidative stress-induced nerve cell death. J Neuroscience 2001, 21:6069-6076. 
54. Sawada H, Ibi M, Kihara T, Urushitani M, Akaike A, Kimura J, Shimohama S: Dopamine D2-type agonist protect mesencephalic neurons from glutamate neurotoxicity: mechanism of neuroprotective treatment against oxidative stress. Ann Neurol 1998, 44:110-119.

55. Rosin C, Colombo S, Calver AA, Bates TE, Skaper SD: Dopamine D2 and D3 receptor agonist limits oligodendrocyte injury caused by glutamate oxidative stress and oxygen/glucose deprivation. Glia 2005, 52:336-343.

56. Milusheva E, Baranyi M, Kittel A, Sperlagh B, Vizi ES: Increased sensitivity of striatal dopamine release to $\mathrm{H}_{2} \mathrm{O}_{2}$ upon chronic rotenone treatment. Free Radic Biol Med 2005, 39:133-142.

57. Snyder SH: Phencyclidine. Nature 1980, 285:335-336.

58. Javitt DC, Zukin SR: Recent advances in the phencyclidine model of schizophrenia. Am J Psychiatry 1991, 148:1301-1308.

59. Tamminga CA: Schizophrenia and glutamatergic transmission. Crit Rev Neurobiol 1998, 12:21-36.

60. Itil T, Keskiner A, Kiremitci N, Holden JMC: Effect of phencyclidine in chronic schizophrenics. Can J Psychiatry 1967, 12:209-212.

61. Lahti AC, Koffel B, Laporte D, Tamminga CA: Subanesthetic doses of ketamine stimulate psychosis in schizophrenia. Neuropsychopharmacology 1994, 13:9-19.

62. Malhotra AK, Pinals DA, Adler CM, Elman I, Clifton A, Pickar D, Breier A: Ketamine-induced exacerbation of psychotic symptoms and cognitive impairment in neuroleptic-free schizophrenics. Neuropsychopharmacology 1997, 17:141-149.

63. Behrens MM, Ali SS, Dao DN, Lucero J, Shekhtman G, Quick KL, Dugan LL: Ketamine-induced loss of phenotype of fast-spiking interneuron is mediated by NADPH-oxidase. Science 2007, 318:1645-1647.

64. Goff DC, Coyle JT: The emerging role of glutamate in the pathophysiology and treatment of schizophrenia. Am J Psychiatry 2001, 158:1367-1377.

65. Xia S, Cai ZY, Thio LL, Kim-Han JS, Dugan LL, Covey DF, Rothman SM: The estrogen receptor is not essential for all estrogen neuroprotection: new evidence from a new analog. Neurobiol Dis 2002, 9:282-293.

66. Zuo DY, Wu YL, Yao WX, Cao Y, Wu CF, Tanaka M: Effect of MK-801 and ketamine on hydroxyl radical generation in the posterior cingulated and retrosplenial cortex of free-moving mice, as determined by in vivo microdialysis. Pharmacol Biochem Behav 2007, 86:1-7.

67. Atlante A, Calissano P, Bobba A, Giannattasio S, Marra E, Passarella S: Glutamate neurotoxicity, oxidative stress and mitochondria. FEBS Lett 2001, 497:1-5.

68. Marini AM, Paul SM: N-methyl-D-aspartate receptor-mediated neuroprotection in cerebellar granule cells requires new RNA and protein synthesis. Proc Natl Sci USA 1992, 89:6555-6559.

69. Marini AM, Rabin SJ, Lipsky RH, Mocchetti I: Activity-dependent release of brain-derived neurotrophic factor underlies the neuroprotective effect of N-methyl-D-aspartate. J Biol Chem 1998, 273:29394-29399.

70. Bhave SV, Ghoda L, Hoffman PL: Brain-derived neurotrophic factor mediates the anti-apoptotic effect of NMDA in cerebellar granule neurons: signal transduction cascades and site of ethanol action. J Neurosci 1999, 19:3277-3286.

71. Xifró X, Falluel-Morel A, Miñano A, Aubert N, Fadó R, Malagelada C, Vaudry D, Vaudry H, Gonzalez B, Rodríguez-Alvarez J: N-methyl-D-aspartate blocks activation of JNK and mitochondrial apoptotic pathway induced by potassium deprivation in cerebellar granule cells. J Biol Chem 2006, 281:6801-6812

72. Köhr G, Seeburg PH: Subtype-specific regulation of recombinant NMDA receptor-channels by protein tyrosine kinases of the src family. J Physiol 1996, 492:445-452.

73. Trotti $D$, Rizzini BL, Rossi D, Haugeto O, Danbolt NC, Volterra A: Neuronal and glial glutamate transporters possess an $\mathrm{SH}$-based redox regulatory mechanism. Eur J Neurosci 1997, 9:1236-1243.

74. Lipton SA, Choi YB, Takahashi H, Zhang D, Li W, Godzik A, Bankston LA: Cysteine regulation of protein function-as exemplified by NMDAreceptor modulation. Trends Neurosci 2002, 25:474-480.

75. Mustafa AK, Kumar M, Selvakumar B, Ho GP, Ehmsen JT, Barrow RK, Amzel LM, Snyder SH: Nitric oxide S-nitrosylates serine racemase, mediating feedback inhibition of D-serine formation. Proc Natl Acad Sci USA 2007, 104:2950-2955.

76. Papadia S, Soriano FX, Léveillé F, Martel MA, Dakin KA, Hansen HH, Kaindl A, Sifringer M, Fowler J, Stefovska V, McKenzie G, Craigon M, Corriveau R, Ghazal P, Horsburgh K, Yankner BA, Wyllie DJ, Ikonomidou C, Hardingham
GE: Synaptic NMDAreceptor activity boosts intrinsic antioxidant defenses. Nat Neurosci 2008, 11:476-487.

77. Arai M, Yuzawa H, Nohara I, Ohnishi T, Obata N, Iwayama Y, Haga S, Toyota T, Ujike H, Arai M, Ichikawa T, Nishida A, Tanaka Y, Furukawa A, Aikawa Y, Kuroda O, Niizato K, Izawa R, Hashimoto K, lyo M, Sora I, Matsushita M, Okazaki Y, Yoshikawa T, Miyata T, Itokawa M: Enhanced carbonyl stress in a subpopulation of schizophrenia. Arch Gen Psychiatry 2010, 67:589-597.

78. Miyata T, Kurokawa K, De Strihou CVY: Advanced glycation and lipidoxidation end products: role of reactive carbonyl compounds generated during carbohydrate and lipid metabolism. J Am Nephrol 2000, 11:1744-1752.

79. Shimizu A, Kurachi M, Yamaguchi N, Torii H, Isaki K: Morbidity risk of schizophrenia to parents and siblings of schizophrenic patients. Jpn J Psychiatry Neurol 1987, 41:65-71.

80. Goldstein JM, Faraone SV, Chen WJ, Tolomiczencko GS, Tsuang MT: Sex differences in the familial transmission of schizophrenia. Br J Psychiatry 1990, 156:819-826.

81. Valero J, Martorell L, Marine J, Vilella E, Labad A: Anticipation and imprinting in Spanish families with schizophrenia. Acta Psychiatr Scand 1998, 97:343-350.

82. Li X, Sundquist J, Sundquist K: Age-specific familial risks of psychotic disorders and schizophrenia: a nation-wide epidemiological study from Sweden. Schizophr Res 2007, 97:43-50.

83. Malaspina D, Harlap S, Fennig S, Heiman D, Nahon D, Feldman D, Susser ES: Advancing paternal age and the risk of schizophrenia. Arch Gen Psychiatry 2001, 58:361-367.

84. Zammit S, Allebeck P, Dalman C, Lundberg I, Hemmingson T, Owen MJ, Lewis G: Paternal age and risk for schizophrenia. Brit J Psychiatry 2003, 183:405-408.

85. Byrne M, Agerbo E, Ewald H, Eaton WW, Mortensen PB: Parental age risk of schizophrenia. A case-control study. Arch Gen Psychiatry 2003, 60:673-678.

86. El-Saadi O, Pedersen CB, McNeil TF, Saha S, Welham J, O'Callaghan E, Cantor-Graae E, Chant D, Mortensen PB, McGrath J: Paternal and maternal age as risk factors for psychosis: findings from Denmark, Sweden and Australia. Schizophr Res 2004, 67:227-236.

87. Sipos A, Rasmussen F, Harrison G, Tynelius P, Lewis G, Leon DA, Gunnell D: Paternal age and schizophrenia; a population based cohort study. BMJ 2004, 329:1070.

88. Gottesman II, Bertelsen A: Confirming unexpressed genotypes for schizophrenia. Risks in the offspring of Fischer's Danish identical and fraternal discordant twins. Arch Gen Psychiatry 1989, 46:867-872.

89. Bakker SC, Hoogendoorn MLC, Selten J-P, Verdujin W, Pearson PL, Sinke RJ, Kahn RS: Neuregulin 1: genetic support for schizophrenia subtypes. Mol Psychiatry 2004, 9:1061-1063.

90. Doi N, Usui C: Are 'high-risk' haplotypes in DTNBP1 and NRG1 resistance genes for schizophrenia? Am J Psychiatry 2006, 163:940-941.

91. Doi N, Itokawa M, Hoshi Y, Arai M, Furukawa A, Hiroshi Ujike, Sora I, Yoshikawa T: A resistance gene in disguise for schizophrenia? Am J Med Genet Part B (Neuropsychiatric Genetics) 2007, 144B:165-173.

92. Lo WS, Xu Z, Yu Z, Pun FW, Ng SK, Chen J, Tong KL, Zhao C, Xu X, Tsang SY, Harano $M$, Stöber $G$, Nimgaonkar $V L$, Xue H: Positive selection within the schizophrenia-associated $\mathrm{GABA}_{\mathrm{A}}$ receptor $\beta_{2}$ gene. PLOS One 2007 2(5):e462.

93. Crepsi B, Summers K, Dorus S: Adaptive evolution of genes underlying schizophrenia. Proc R Soc B 2007, 274:2801-2810.

94. Kulkarni J, Fink G: Hormones and psychosis. In Women and schizophrenia. Edited by Castle DL, McGrath J, Kulkarni J. Cambridge: Cambridge University Press; 2000:51-66.

95. Goldstein JM, Lewine RRJ: Overview of sex differences in schizophrenia: where have we been and where do we go from? In Women and schizophrenia. Edited by Castle DL, McGrath J, Kulkarni J. Cambridge: Cambridge University Press; 2000:111-143.

96. Behl C: Oestrogen as a neuroprotective hormone. Nat Rev Neurosci 2002, 3:433-442.

97. Strehlow K, Rotter S, Wassmann S, Adam O, Grohé C, Laufs K, Böhm M, Nickenig $G$ : Modulation of antioxidant enzyme expression and function by estrogen. Circ Res 2003, 93:170-173.

98. Pajović SB, Saićić ZS, Spasić MB, Petrović VM: The effect of ovarian hormones on antioxidant enzyme activities in the brain of male rats. Physiol Res 2003, 52:189-194. 
99. Brann DW, Dhandapani K, Wakade C, Mahesh VB, Khan M: Neurotrophic and neuroprotective actions of estrogen: basic mechanism and clinical implications. Steroids 2007, 72:381-405.

100. Monje $P$, Boland R: Subcellular distribution of native estrogen receptor alpha and beta isoforms in rabbit uterus and ovary. J Cell Biochem 2001, 82:467-479.

101. Chen JQ, Delannoy M, Cooke C, Yager JD: Mitochondrial localization of ERalpha and ERbeta in human MCF7 cells. Am J Physiol 2004, 286: E1011-E1022.

102. Stirone C, Duckles SP, Krause DN, Procaccio V: Estrogen increases mitochondrial efficiency and reduces oxidative stress in cerebral blood vessels. Mol Pharmacol 2005, 68:959-965.

103. Susser E, Neugebauer R, Hoek HW, Brown AS, Lin S, Labovitz D, Gorman JM: Schizophrenia after prenatal famine. Further evidence. Arch Gen Psychiatry 1996, 53:25-31.

104. Brown AS, Bottiglieri T, Schaefer CA, Quesenberry CP Jr, Liu L, Bresnahan M, Susser ES: Elevated prenatal homocysteine levels as a risk factor for schizophrenia. Arch Gen Psychiatry 2007, 64:31-39.

105. Opler MGA, Susser ES: Fetal environment and schizophrenia. Environment Health Perspectives 2005, 113:1239-1242.

106. Limosin F, Rouillon F, Payan C, Cohen J-M, Strub N: Prenatal exposure to influenza as a risk factor for adult schizophrenia. Acta Psychiatr Scand 2003, 107:331-335.

107. Brown AS, Begg MD, Gravenstein S, Schaefer CA, Wyatt RJ, Bresnahan M, Babulas VP, Susser ES: Serologic evidence of prenatal influenza in the etiology of schizophrenia. Arch Gen Psychiatry 2004, 61:774-780.

108. Brown AS, Shaefer C, Quesenberry CP Jr, Liu L, Babulas VP, Susser E: Maternal exposure to toxoplasmosis and risk of schizophrenia in adult offspring. Am J Psychiatry 2005, 162:767-773.

109. Dalman C, Allebeck P, Gunnell D, Harrison G, Kristensson K, Lewis G, Lofving S, Rasmussen F, Wicks S, Karlsson H: Infections in the CNS during childhood and the risk of subsequent psychotic illness: a cohort study of more than one million Swedish subjects. Am J Psychiatry 2008, 165:59-65.

110. Akaike T, Ando M, Oda T, Doi T, ljiri S, Araki S, Maeda H: Dependence on $\mathrm{O}_{2}^{-}$ generation by xanthine oxidase of pathogenesis of influenza infection in mice. J Clin Invest 1990, 85:739-745.

111. Buffinton GD, Christen S, Peterhans $E$, Stocker R: Oxidative stress in lungs of mice infected with influenza A virus. Free Radc Res Commun 1992, 16:99-110.

112. Edlund C, Holemberg G, Dallnen G, Norrby E, Kristensson K: Ubiquinone-10 protect neurons from virus-induced degenerations. J Neurochem 1994, 63:634-639.

113. Speir E, Yu ZX, Ferrans VJ, Huang ES, Epstein SE: Aspirin attenuates cytomegalovirus infectivity and gene expression mediated by cyclooxigenase-2 in coronary artery smooth muscle cells. Circ Res 1998, 83:210-216.

114. He L, Perkins GA, Poblenz AT, Harris JB, Hung M, Ellisman MH, Fox DA: $\mathrm{Bcl}-\mathrm{x}_{\mathrm{L}}$ overexpression blocks bax-mediated mitochondrial contact site formation and apoptosis in rod photoreceptors of lead-exposed mice. Proc Natl Acd Sci USA 2003, 100:1022-1027.

115. Berger MM, Jia XY, Legay V, Aymard M, Tilles JG, Lina B: Nutrition- and virus-induced stress repress the expression of manganese superoxide dismutase in vitro. Exp Biol Med 2004, 229:843-849.

116. Gupta P, Narang M, Banerjee BD, Basu S: Oxidative stress in term small for gestational age neonates born to undernourished mothers: a case controlled study. BMC Pediatr 2004, 4:14-20.

117. Zaki MH, Akutu T, Akaike T: Nitric oxide-induced nitrative stress involved in microbial pathogenesis. J Pharmacol Sci 2005, 98:117-129.

118. Kruman II, Culmsee C, Chan SL, Kruman Y, Guo Z, Penix L, Mattson MP Homocysteine elicits a DNA damage response in neurons that promotes apoptosis and hypersensitivity to excitotoxicity. I NeurosCi 2000, 20:6920-6026.

119. Wang J, Wu J, Zhang Z: Oxidative stress in mouse brain exposed to lead Ann Occup Hyg 2006, 50:405-409.

120. Poncet D, Pauleau AL, Szabadkai G, Vozza A, Scholz SR, Le Bras M, Brière JJ, Jalil A, Le Moigne R, Brenner C, Hahn G, Wittig I, Schägger H, Lemaire C, Bianchi K, Souquère S, Pierron G, Rustin P, Goldmacher VS, Rizzuto R, Palmieri F, Kroemer G: Cytopathic effects of cytomegalovirus-encoded apoptosis inhibitory protein vMIA. J Cell Biol 2006, 174:985-996.
121. Chang CM, Yu CC, Lu HT, Chou YF, Huang RF: Folate deprivation promotes mitochondrial oxidative decay: DNA large deletions, cytochrome c oxidase dysfunction, membrane depolarisation and superoxide overproduction in rat liver. Br J Nutr 2007, 97:855-863.

122. Nishikawa $Y$, Kawase $O$, Vielemeyer $O$, Suzuki $H$, Joiner KA, Xuan $X$ Nagasawa $H$ : Toxoplasma gondii infection induces apoptosis in noninfected macrophages: role of nitric oxide and other soluble factors. Parasite Immunol 2007, 29:375-385.

123. Shanklin DR, Sibai BM: Ultrastructural aspects of preeclampsia. II. Mitochondrial changes. Am J Obstet Gynecol 1990, 163:943-953.

124. Barton JR, Hiett AK, O'Connor WM, Nissen SE, Greene JW: Endomyocardial ultrastructural findings in preeclampsia. Am J Obstet Gynecol 1991, 165:389-391.

125. Furui $T$, Kurauchi O, Tanaka M, Mizutani S, Ozawa T, Tomoda Y: Decrease in cytochrome c oxidase and cytochrome oxidase subunit I messenger RNA levels in preeclamptic pregnancies. Obstet Gynecol 1994, 84:283-288.

126. Torbergsen T, Oian P, Mathiesen E, Borud O: Pre-eclampsia - A mitochondrial disease? Acta Obstet Gynecol Scand 1989, 68:145-148.

127. Folgero T, Storbakk N, Torbergsen T, Oian P: Mutations in mitochondrial transfer ribonucleic acid genes in preeclampsia. Am J Obstet Gynecol 1996, 174:1626-1630.

128. Dalman C, Allebeck P, Cullberg J, Grunewald C, Köster M: Obstetric complications and the risk of schizophrenia. A longitudinal study of a national birth cohort. Arch Gen Psychiatry 1999, 56:234-240.

129. Cannon M, Jones PB, Murray RM: Obstetric complications and schizophrenia: historical and meta-analytic review. Am J Psychiatry 2002, 159:1080-1092.

130. Rapoport JL, Addington AM, Fragnau S: The neurodevelopmental model of schizophrenia: update 2005. Mol Psychiatry 2005, 10:434-449.

131. Sobel D: Infant malformations and mortality in children of schizophrenic parents. Psychiatr Q 1961, 35:60-64.

132. Rieder $R Q$, Rosenthal $D$, Wender $P$, Blumenthal $H$ : The offspring of schizophrenics, I: fetal and neonatal deaths. Arch Gen Psychiatry 1975, 32:200-211.

133. Modrzewska K: The offspring of schizophrenic parents in a North Swedish isolate. Clin Genet 1980, 17:191-201.

134. Hitchon CA, El-Gabalawy HS: Oxidation in rheumatoid arthritis. Arthritis Res Ther 2004, 6:265-278.

135. Remans $\mathrm{PH}$, van Oosterhout M, Smeets TJ, Sanders M, Frederiks WM, Reedquist KA, Tak PP, Breedveld FC, van Laar JM: Intracellular free radical production in synovial T lymphocytes from patients with rheumatoid arthritis. Arthritis Rheum 2005, 52:2003-2009.

136. Vinogradov S, Gottesman II, Moises HW, Nicol S: Negative association between schizophrenia and rheumatoid arthritis. Schizophr Bull 1991, 17:669-678

137. Rubinstein G: Schizophrenia, rheumatoid arthritis and natural resistance genes. Schizophr Res 1997, 25:177-181.

138. Oken RJ, Schulzer M: At issue: schizophrenia and rheumatoid arthritis: the negative association revised. Schizophr Bull 1999, 25:625-638.

139. Samper $E$, Nicholls DG, Melov S: Mitochondrial oxidative stress causes chromosomal instability of mouse embryonic fibroblasts. Aging Cell 2003, 2:277-285.

140. Ragu S, Faye G, Iraqui I, Masurel-Heneman A, Kolodner RD, Huang M-E: Oxygen metabolism and reactive oxygen species cause chromosomal rearrangements and cell death. Proc Natl Acad Sci USA 2007, 104:9747-9752

141. Macintyre DJ, Blackwood DHR, Porteous DJ, Pickard BS, Muir WJ: Chromosomal abnormalities and mental illness. Mol Psychiatry 2003, 8:275-287.

142. Pulver AE, Nestadt G, Goldberg R, Shprintzen RJ, Lamacz M, Wolyniec PS Morrow B, Karayiorgou M, Antonarakis SE, Housman D, et al: Psychotic illness in patients diagnosed with velo-cardio-facial syndrome and their relatives. J Nerv Ment Dis 1994, 182:476-478.

143. Murphy KC, Jones LA, Owen MJ: High rates of schizophrenia in adults with velo-cardio-facial syndrome. Arch Gen Psychiatry 1999, 56:940-945.

144. Walsh T, McClellan JM, McCarthy SE, Addington AM, Pierce SB, Copper GM Nord AS, Kusenda M, Malhortra D, Bhandari A, Stray SM, Rippery CF, Roccanova P, Makarov V, Lakshmi B, Finling RL, Sikich L, Stromerg T, Merriman B, Gogtay N, Butler P, Eckstrand K, Noory L, Gochman P, Long R, 
Chen Z, Davis S, Baker C, Eichler EE, Meltzer PS, Nelson SF, Singleton AB, Lee MK, Rapoport JL, King MC, Sebat J: Rare structural variants disrupt multiple genes in neurodevelopmental pathways in schizophrenia. Science 2008, 320:539-543.

145. Xu B, Roos JL, Levy S, van Rensburg EJ, Gogos JA, Karayiorgou M: Strong association of de novo copy number mutations with sporadic schizophrenia. Nat Genet 2008, 40:880-885.

146. Awadalla P, Gauthier J, Myers RA, Casals F, Hamdan FF, Griffing AR, Côté M, Henrion E, Spiegelman D, Tarabeux J, Piton A, Yang Y, Boyko A, Bustamante C, Xiong L, Rapoport JL, Addington AM, DeLisi JLE, Krebs M-O, Joober R, Millet B, Fombonne É, Mottron L, Zilversmit M, Keebler J, Daoud H, Marineau C, RoyGagnon M-H, Dubé M-P, Eyre-Walker A, Drapeau P, Stone EA, Lafrenière RG, Rouleau GA: Direct measure of the de novo mutation rate in autism and schizophrenia cohorts. Am J Hum Genet 2010, 87:316-324.

147. Smith CL, Bolton A, Nguyen G: Genomic and epigenomic instability, fragile sites, schizophrenia and autism. Current Genomics 2010, 11:447-469.

148. Demirhan O, Tastemir D, Sertdemir Y: Chromosomal fragile sites in schizophrenic patients. Genetika 2006, 42:985-992.

149. Ohsawa I, Ishikawa M, Takahashi K, Watanabe M, Nishimaki K, Yamagata K, Katsura K, Katayama Y, Asoh S, Ohta S: Hydrogen acts as a therapeutic antioxidant by selectively reducing cytotoxic oxygen radicals. Nat Med 2007, 13:688-694.

150. Lindholm E, Cavelier L, Howell WM, Eriksson I, Jalonen P, Adolfsson R, Blackwood DH, Muir WJ, Brookes AJ, Gyllensten U, Jazin EE: Mitochondrial sequence variants in patients with schizophrenia. Eur J Hum Genet 1997, 5:406-412.

151. Marchbanks RM, Ryan M, Day IN, Owen M, McGuffin P, Whatley SA: A mitochondrial DNA sequence variant associated with schizophrenia and oxidative stress. Schizophr Res 2003, 65:33-38.

152. Martorell L, Segués T, Folch G, Valero J, Joven J, Labad A, Vilella E: New variants in the mitochondrial genomes of schizophrenic patients. Eur J Hum Genet 2006, 14:520-528.

153. Bamne MN, Talkowski ME, Moraes CT, Manuck SB, Ferrell RE, Chowdari KV, Nimgaonkar VL: Systematic association studies of mitochondrial DNA variations in schizophrenia: focus on the ND5 gene. Schizophr Bull 2008, 34:458-465

154. Rollins B, Martin MV, Sequeira PA, Moon EA, Morgan LZ, Watson SJ, Schatzberg A, Akil H, Myers RM, Jones EG, Wallace DC, Bunney WE, Vawter MP: Mitochondrial variants in schizophrenia, bipolar disorder, and major depressive disorder. PLoS One 2009, 4(3)::4913.

155. Ueno H, Nishigaki Y, Kong QP, Fuku N, Kojima S, Iwata N, Ozaki N, Tanaka M: Analysis of mitochondrial DNA variants in Japanese patients with schizophrenia. Mitochondrion 2009, 9:385-393.

156. Ichikawa T, Arai M, Miyashita M, Arai M, Obata N, Nohara I, Oshima K, Niizato K, Okazaki Y, Doi N, Itokawa M: Schizophrenia: maternal inheritance and heteroplasmy of mtDNA mutations. Mol Genet Metab 2012, 105:103-109.

157. Pulkes T, Hanna MG: Clinical aspects of mitochondrial encephalomyopathies. In Genetics of mitochondrial diseases. Edited by Holt IJ. New York: Oxford University Press; 2003:87-109.

158. Bertolin C, Magri C, Barlati S, Vettori A, Perini Gl, Peruzzi P, Mostacciuolo ML, Vazza G: Analysis of complete mitochondrial genomes of patients with schizophrenia and bipolar disorder. J Hum Genet 2011, 56:869-872.

159. Sue CM, Quigley A, Katsabanis S, Kapsa R, Crimmins DS, Byrne E, Morris JGL: Detection of MELAS A3243G point mutation in muscle, blood and hair follicles. J Neurol Sci 1998, 161:36-39.

160. Risch N, Reich EW, Wishnick MM, McCarthy JG: Spontaneous mutation and parental age in humans. Am J Hum Genet 1987, 41:218-248.

161. Ohashi J, Tokunaga K: The expected power of genome-wide linkage disequilibrium testing using single nucleotide polymorphism markers for detecting a low-frequency disease variant. Ann Hum Genet 2002, 66:297-306.

doi:10.1186/1744-9081-8-28

Cite this article as: Doi et al: Paradox of schizophrenia genetics: is a paradigm shift occurring?. Behavioral and Brain Functions 2012 8:28. 